Article

\title{
Extracts from Eleutherococcus senticosus (Rupr. et Maxim.) Maxim. Roots: A New Hope Against Honeybee Death Caused by Nosemosis
}

\author{
Aneta A. Ptaszyńska ${ }^{1, * \mathbb{D}}$ and Daniel Załuski ${ }^{2}$ D \\ 1 Department of Immunobiology, Institute of Biological Sciences, Faculty of Biology and Biotechnology, \\ Maria Curie-Skłodowska University, Akademicka 19 Str., 20-033 Lublin, Poland \\ 2 Department of Pharmaceutical Botany and Pharmacognosy, Ludwik Rydygier Collegium Medicum, \\ Nicolaus Copernicus University, Marie Curie-Skłodowska 9, 85-094 Bydgoszcz, Poland; \\ daniel_zaluski@onet.eu \\ * Correspondence: aneta.ptaszynska@poczta.umcs.lublin.pl; Tel.: +48-537-5050
}

Academic Editors: Barbara Hawrylak-Nowak, Sławomir Dresler and Thomas J. Schmidt

Received: 22 July 2020; Accepted: 23 September 2020; Published: 28 September 2020

\begin{abstract}
Pollinators, the cornerstones of our terrestrial ecosystem, have been at the very core of our anxiety. This is because we can nowadays observe a dangerous decline in the number of insects. With the numbers of pollinators dramatically declining worldwide, the scientific community has been growing more and more concerned about the future of insects as fundamental elements of most terrestrial ecosystems. Trying to address this issue, we looked for substances that might increase bee resistance. To this end, we checked the effects of plant-based adaptogens on honeybees in laboratory tests and during field studies on 30 honeybee colonies during two seasons. In this study, we have tested extracts obtained from: Eleutherococcus senticosus, Garcinia cambogia, Panax ginseng, Ginkgo biloba, Schisandra chinensis, and Camellia sinensis. The $75 \%$ ethanol E. senticosus root extract proved to be the most effective, both as a cure and in the prophylaxis of nosemosis. Therefore, Eleutherococcus senticosus, and its active compounds, eleutherosides, are considered the most powerful adaptogens, in the pool of all extracts that were selected for screening, for supporting immunity and improving resistance of honeybees. The optimum effective concentration of $0.4 \mathrm{mg} / \mathrm{mL}$ E. senticosus extract responded to c.a. $5.76,2.56$ and $0.07 \mu \mathrm{g} / \mathrm{mL}$ of eleutheroside B, eleutheroside $E$ and naringenin, respectively. The effect of E. senticosus extracts on honeybees involved a similar adaptogenic response as on other animals, including humans. In this research, we show for the first time such an adaptogenic impact on invertebrates, i.e., the effect on honeybees stressed by nosemosis. We additionally hypothesised that these adaptogenic properties were connected with eleutherosides-secondary metabolites found exclusively in the Eleutherococcus genus and undetected in other studied extracts. As was indicated in this study, eleutherosides are very stable chemically and can be found in extracts in similar amounts even after two years from extraction. Considering the role bees play in nature, we may conclude that demonstrating the adaptogenic properties which plant extracts have in insects is the most significant finding resulting from this research. This knowledge might bring to fruition numerous economic and ecological benefits.
\end{abstract}

Keywords: honeybee; Apis mellifera; Eleutherococcus senticosus; Garcinia cambogia; Panax ginseng; Ginkgo biloba; Schisandra chinensis; Camellia sinensis; fumagillin; eleutherosides; adaptogenic herbs; insectageddon

\section{Introduction}

The very existence of humans on the planet depends on other organisms' well-being, also on insects-especially the main managed pollinator-the honeybee $[1,2]$. We are now living in the 
Anthropocene-a geological epoch characterised by the commencement of a significant human impact on the Earth's geology and ecosystems [3-5]. It is marked by the sixth mass extinction [6]. Insects suffer an extinction rate that is up to 8 times higher than in other groups of most endangered species [7]. In Germany, during the routine monitoring of protected areas, scientists found that within 27 years of researching the same sites, insect biomass decreased by $76 \%$, and in the middle of the summer, the decline in flying insect biomass was up to $82 \%$ [8]. Similar trends have been observed around the world. Sánchez-Bayo and Wyckhuys [9] compared 73 long-term insect tests in their review and showed that the rate of biodiversity loss in this group of animals is so large that $40 \%$ of insect species in the world may die over the next few years. Due to its enormous impact on the environment, this decrease in the number and biodiversity of insect populations is sometimes called the insectageddon. This rapid insect extinction is connected with malnutrition, enormous pesticide overuse and diseases attacking weakened insects. Nosemosis is one of such diseases attacking weakened honeybees. It is caused by microsporidia from the Nosema genus. Until recently, only two types of Nosema species were thought to parasitize bees, i.e., Nosema apis and N. ceranae $[10,11]$, however, the third genus, N. neumanni, was described in 2017 [12]. Nosemosis negatively alters the gut epithelium renewal rate [13] and creates a layer of mature spores on the intestine surface [14], which leads to bee malnutrition and changes in the composition of microelements [15]. Nosemosis also changed honeybee intestinal microbiome contents, both on bacterial [16] and yeast [17] levels. Furthermore, it causes impairments of many gland functions [18-20], accelerates age polyethism in young honeybees [19], decreases the level of hormone secretion and causes anatomical changes in bee queens' ovaries, and finally, it affects fertility and the survival rate in older honeybee males [21-23]. All these factors affect both individual honeybees and the whole bee colony, decreasing its survival rate [13-23].

Therefore, various actions that increase pollinators' wellbeing are important, such as creating flower strips, pollinator-friendly gardens, reducing pesticide applications and raising public awareness of pollinators' importance. It is also essential to look for various ways to enhance the immunity of pollinators in order to help them survive. Some of the substances increasing immunity can be single plant-derived secondary metabolites, which when transported into nectar, can be beneficial for pollinators [24]. Other agents that might look like effective 'bee medicines' can be natural products such as plant extracts, essential oils and phytochemicals [25]. The following extracts have been tested to date, albeit without much success: Achillea alpina (Ledeb), Achyranthes japonica (Miq.), Allium senescens L. var. senescens, Amaranthus mangostanys L., Aster tataricus L.f., Astilboides tabularis (Hemsl.) Engl., Astragalus membranaceus Bunge var. membranaceus, Cinnamomum cassia (L.) J. Presl, Cirsium nipponicum (Maxim.) Makino, Cryptocarya alba (Molina) Looser, Cyrtomium fortune J. Sm., Disporum uniflorum Baker, Eucalyptus citridora (Hook.) K.D. Hill, L.A.S.Johnson, Lythrum salicaria L., Mentha arvensis L., Perilla frutescens var. acuta Kudo, Physalis alkekengi var. francheti (Mast.) Hort, Rheum undulatum L., Symphytum officinale L. and Veratrum oxysepalum Turcz. [26,27]. It is worth emphasising that only extracts from two representatives of the Compositae family, Artemisia dubia (Wall.) and Aster scaber Thunberg, at non-toxic concentrations, proved to show anti-nosemosis effects [28,29]. In several studies, essential oils such as mint (Mentha pepper L.), melissa (Melissa officinalis L.), coriandrum (Coriander satioum L.), thyme (Satureja hortensis L.) oils, other phytochemicals such as caffeine, clove oil, gallic acid, kaempferol and p-coumaric acid, and even propolis expanded honeybee longevity and to some extent, reduced nosemosis levels [27-35]. Such phytochemicals as clove oil, laurel extract and sulforaphane, moderately decreased Nosema-infection, but at the same time, strongly reduced honeybee lifespan [33,36,37]. Other tested phytochemicals, such as amygdalin, anabasine, aucubin, catalpol, nicotine and thymol, had no effect against Nosema infection [33,36,37].

Nonetheless, new 'bee medicines' should be searched for, especially now when fumagillin is no longer effective in the treatment of nosemosis as $N$. ceranae might evade it [38,39], and because its use is prohibited in EU countries (A maximum residue level, MRL; Commission Regulation, EU, 2010, no. 37/2010). The use of medicines in apiculture should be safe both for honeybees and for humans. Fumagillin is the cause of alterations to the ultrastructure of hypopharyngeal glands in bees and causes 
chromosomal aberrations, and carcinogenicity in humans [40]. Therefore, there is a significant demand for a new medication that safely and effectively treats honeybee colonies infected with $N$. ceranae.

Looking for substances that would increase bee resistance, we checked the effects of plant-based adaptogens, which are defined as natural compounds or plant extracts that increase the adaptability, resilience and survival of living organisms subjected to stress [41]. This study, being an element of a program searching for bioactive constituents, was aimed at determining whether adaptogenic plants (Eleutherococcus senticosus (Rupr. et Maxim.) Maxim. and Oliv, Eleutherococcus henryi Oliv., Garcinia gummi-gutta (L.) N. Robson, Panax ginseng C.A. Meyer, Schisandra chinensis (Turcz.) Baill., Camellia sinensis (L.) Kuntze and Ginkgo biloba L.) might be effective and safe candidates for the treatment and prophylaxis of nosemosis.

\section{Results}

We tested six adaptogenic plant extracts, i.e., Eleutherococcus senticosus, Garcinia cambogia, Panax ginseng, Ginkgo biloba, Schisandra chinensis and Camellia sinensis. The $75 \%$ ethanol E. senticosus root extract rich in eleutherosides proved to be most effective, both as a cure and in the prophylaxis of nosemosis. The minimum effective dose was established at $0.4 \mathrm{mg} / \mathrm{mL}$ of $E$. senticosus extract. It proved to be optimal for honeybee nosemosis treatment and prophylaxis in laboratory studies and field tests conducted on 30 honeybee colonies trough two seasons.

\subsection{Results of Cage Tests}

Emerging honeybees were divided randomly into three treatment variants, " $A$ ", " $B$ ", and " $C$ " (all acronyms are defined in Supplementary Materials Tables S1-S3):

A. Honeybees in variant "A" (control, impact of extracts on uninfected honeybees) served as a control and were not infected with N. ceranae. Feeding group SS (sucrose syrup) served as a negative control with uninfected honeybees fed solely with 1:1 w:v [1:1 weight:volume sugar:water] sucrose solution and not treated with extracts.

B. In variant "B" (impact of extracts on the treatment of nosemosis), to check whether the supplementation of honeybee diets with extracts influences the course of nosemosis, firstly, honeybees were Nosema ceranae-infected, and subsequently fed with a sucrose solution, containing extracts. Feeding group SS served as a negative control with Nosema ceranae-infected honeybees fed solely with a 1:1 w:v sucrose solution, not treated with extracts, and Fum (fumagillin), served as a positive control in the treatment of nosemosis.

C. In variant " $\mathrm{C}$ " (impact of extracts on the prevention of nosemosis), to check whether the supplementation of honeybee diets with extracts protects honeybees against nosemosis, firstly, honeybees were fed with a sucrose solution supplemented with extracts, and after that, were infected with $N$. ceranae spores. Feeding group SS served as a negative control with Nosema ceranae-infected honeybees fed solely with a 1:1 w:v sucrose solution and not treated with extracts.

\subsubsection{Results of Cage Tests: Screening of Commercial Plant Extracts}

We compared data from all three treatment methods (A, B, and C, acronyms are defined in Supplementary Materials Table S1) of conducted experiments (Table 1, Figure 1), i.e., A (lifespan), B (Nosema-treatment), C (Nosema-prevention), to choose the best extract for further experiments. In variant $\mathrm{B}$, honeybee lifetime extension (with $p<0.05$ ) was observed after feeding with all tested plant extracts. However, not all extracts reduced the level of nosemosis. This may have been caused by better nutrition of infected honeybees that were fed with additional extracts compared to the control group fed only with the sucrose solution.

Commercial extracts from Eleutherococcus senticosus (groups: ESa and Esb, Figure 1) had the best impact on honeybees out of all the studied commercial extracts. Honeybees were fed with extracts 
in concentrations of 0.2 and $1 \mathrm{mg}$ of active compound in $1 \mathrm{~mL}$ of the sucrose solution. The $1 \mathrm{mg} / \mathrm{mL}$ E. senticossus extract had the most powerful impact on the level of nosemosis, but the concentration of $0.2 \mathrm{mg} / \mathrm{mL}$ was more eagerly consumed by honeybees and more efficiently prolonged honeybee lifespans than $1 \mathrm{mg} / \mathrm{mL}$ (groups: ESa and Esb, Figure 1). Therefore, we chose E. senticosus extracts for further experiments and decided to check the dose higher than $0.2 \mathrm{mg} / \mathrm{mL}$, i.e., $0.4 \mathrm{mg} / \mathrm{mL}$.

Commercial extract from Garcinia gummi-gutta (groups: GGa and GGb, Figure 1) was consumed in similar amounts as in the control group (SS) fed with the pure sucrose solution. Mortality was also similar to the control group (SS) in all three (A, B, C) experiment variants. Additionally, G. gummi-gutta extract reduced the level of nosemosis both in the variant $B$ (course) and $C$ (prevention).

Commercial extract from Panax ginseng (groups: PGa and PGb, Figure 1) was only reluctantly consumed by honeybees. In variant A, P. ginseng in the concentration of $1 \mathrm{mg} / \mathrm{mL}$ (group PGb) increased mortality of honeybees. In variants B and C, the mortality was similar to the mortality observed in the control group (SS). Both in variant B (course) and C (prevention), P. ginseng extract slightly reduced the nosemosis level in comparison to the control (SS).

Commercial extract from Schisandra chinensis (groups: SCa and SCb, Figure 1) was consumed in a similar amount as in the control group (SS) fed with the pure sugar syrup. Mortality was also similar to the control group (SS) in all three (A, B, C) experiment variants. Additionally, S. chinensis extract reduced the nosemosis level both in variant $B$ (course) and $C$ (prevention).

Commercial extract from Camellia sinensis (groups: CSa and CSb, Figure 1) was only reluctantly consumed by honeybees. In variant A, C. sinensis in the concentration of $1 \mathrm{mg} / \mathrm{mL}$ (group CSb) increased mortality of honeybees. In variants B and C, the mortality was similar to the mortality observed for the control group (SS). Additionally, C. sinensis did not reduce the nosemosis level in comparison to the control (SS) both in variant B (course) and C (prevention).

Commercial extract from Ginkgo biloba (groups: GBa and GBb, Figure 1) was consumed in a similar amount as in the control group (SS) fed with the pure sucrose solution. Mortality was also similar to the control group (SS) in all three (A, B, C) experiment variants. G. biloba did not reduce the level of nosemosis in comparison to the control (SS) neither in variant B (course) nor in C (prevention).

Fumagillin (Fum, Figure 1) was consumed in a slightly smaller amount in variant $A$ and in a similar amount in the control group (SS) fed with the pure sucrose solution in other variants. In variant A, fumagillin increased mortality of honeybees. In variants B and C, mortality was similar to the mortality observed for the control group (SS). In variant B (nosemosis treatment), fumagillin strongly reduced the level of nosemosis but it was ineffective in the prevention of nosemosis (variant C).

Table 1. Results of the cage tests: Screening of commercial plant extracts. The honeybee longevity: ++ the extract which was most efficient in the prolongation of the honeybee lifespan, + the extract prolonged the honeybee lifespan in comparison to the control group, - the extract reduced the honeybee lifespan in comparison to the control group. Reducing the level of nosemosis: ++ the extract which was most efficient in reducing the level of nosemosis, + the extract reduced the level of nosemosis in comparison to the control group, - the extract did not reduce the level of nosemosis in comparison to the control group. Food intake: + sucrose syrup with addition of the extract was consumed in a similar level as the pure sucrose syrup in the control group, - the extract was reluctantly consumed by honeybees in comparison to the control group.

\begin{tabular}{cccc}
\hline & Honeybee Longevity & Nosema Infection & Food Intake \\
\hline Eleutherococcus senticosus (ES) & ++ & ++ & + \\
Garcinia gummi-gutta (GG) & + & + & + \\
Panax ginseng (PG) & - & + & - \\
Schisandra chinensis (SC) & + & + & + \\
Camellia sinensis (CS) & - & - & - \\
Ginkgo biloba (GB) & + & - & + \\
Fumagillin (Fum) & - & ++ & + \\
\hline
\end{tabular}




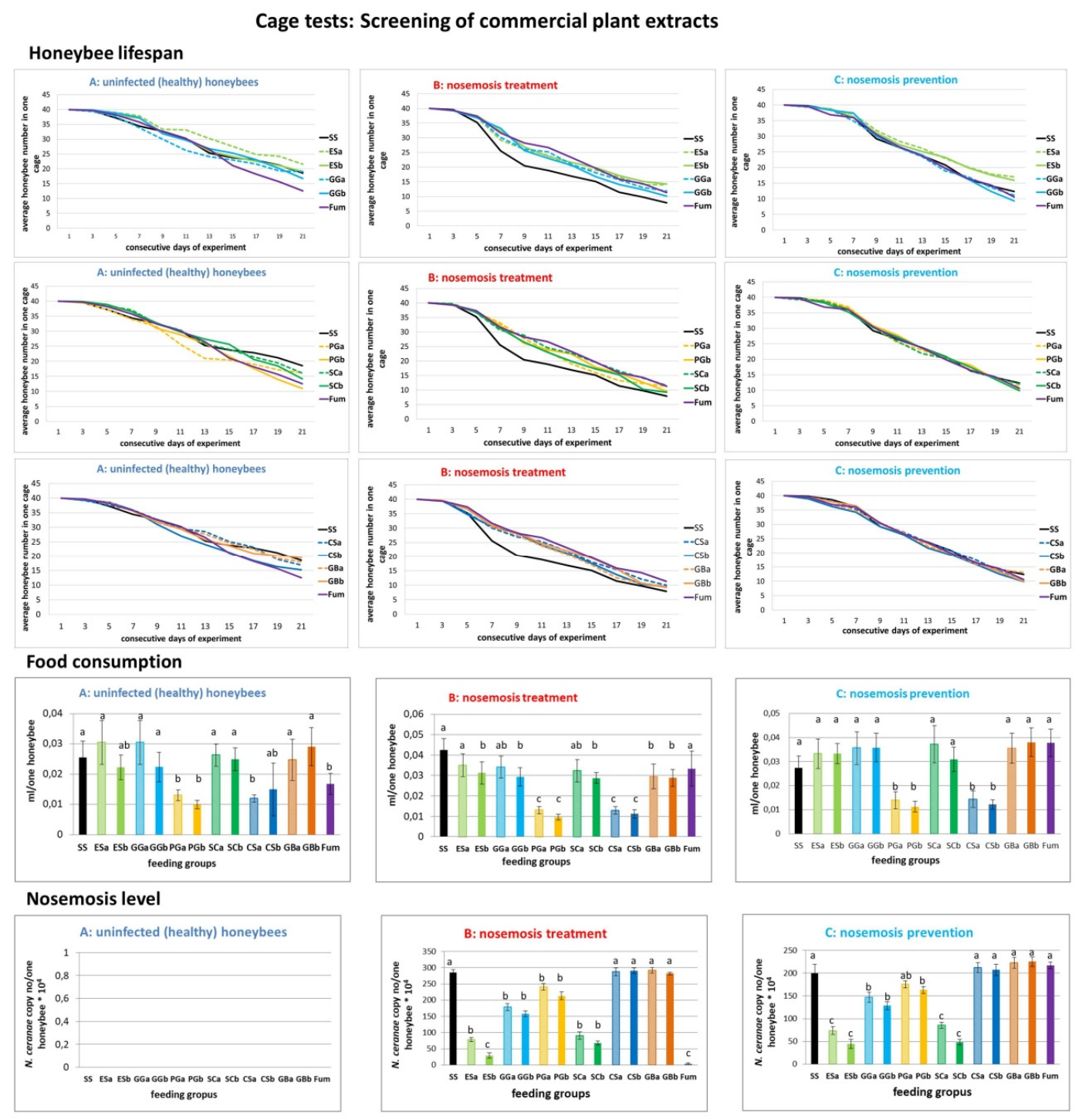

Figure 1. Results of cage tests: Screening of commercial plant extracts. Data illustrated honeybee lifespan, food consumption and nosemosis level in all three variants of experiments conducted, i.e., (A) uninfected honeybees, (B) treatment of nosemosis and (C) prevention of nosemosis were compared. Lowercase letters $(a, b, c)$ indicate significant differences between the group fed pure sucrose syrup without extracts (SS) and the groups fed with additions of extracts (at least $p \leq 0.005$ for the honeybee lifespan and nosemosis level, and $p \leq 0.05$ for food consumption) (analysis of variance (ANOVA), Tukey test). Error bars denote a confidence interval (CI). Feeding groups (acronyms are defined in Supplementary Materials Table S1): (SS-sucrose syrup) control, pure sucrose syrup without extracts, (ESa) sucrose syrup supplemented with $0.2 \mathrm{mg} / \mathrm{mL}$ of commercial extracts of E. senticosus, (ESb) sucrose syrup supplemented with $1 \mathrm{mg} / \mathrm{mL}$ of commercial extracts of E. senticosus, (GGa) sucrose syrup supplemented with $0.2 \mathrm{mg} / \mathrm{mL}$ of commercial extracts of G. gummi-gutta, (GGb) sucrose syrup supplemented with $1 \mathrm{mg} / \mathrm{mL}$ of commercial extracts of G. gummi-gutta, (PGa) sucrose syrup supplemented with $0.2 \mathrm{mg} / \mathrm{mL}$ of commercial extracts of $P$. ginseng, (PGb) sucrose syrup supplemented with $1 \mathrm{mg} / \mathrm{mL}$ of commercial extracts of $P$. ginseng, (SCa) sucrose syrup supplemented with $0.2 \mathrm{mg} / \mathrm{mL}$ of commercial extracts of $S$. chinensis, $(\mathrm{SCb})$ sucrose syrup supplemented with $1 \mathrm{mg} / \mathrm{mL}$ of commercial extracts of $S$. chinensis, (CSa) sucrose syrup supplemented with $0.2 \mathrm{mg} / \mathrm{mL}$ of commercial extracts of C. sinensis, (CSb) sucrose syrup supplemented with $1 \mathrm{mg} / \mathrm{mL}$ of commercial extracts of $C$. sinensis, (GBa) sucrose syrup supplemented with $0.2 \mathrm{mg} / \mathrm{mL}$ of commercial extracts of $G$. biloba, $(\mathrm{GBb})$ sucrose syrup supplemented with $1 \mathrm{mg} / \mathrm{mL}$ of commercial extracts of G. biloba, and (Fum) fumagillin as a positive control in the treatment of nosemosis. 
2.1.2. Results of Cage Tests: Screening for the Best Method to Obtain the Eleutherococcus Extract

Laboratory extracts of E. senticosus (ES) and E. henryi (EH) were obtained using three different methods of extraction, i.e., water, chloroform and ethanol from these plants' roots and fruits (Table 2, acronyms are defined in Supplementary Materials Table S2). E. senticossus root ethanol extract prolonged bee lifespan, strongly reduced level of nosemosis and in variant A, was consumed at a comparable level to the control group fed only the sucrose syrup (Figure 2). Generally, E. senticossus root ethanol extract was the most effective in prophylaxis and in the treatment of nosemosis. Therefore, we chose the E. senticosus root ethanol extract for further experiments.

Table 2. Designation of research groups under screening for the best method of obtaining the Eleutherococcus extract (acronyms are defined in Supplementary Materials Table S2).

\begin{tabular}{cccc}
\hline $\begin{array}{c}\text { The Type of Extraction } \\
\text { Plant Species }\end{array}$ & Water & Chloroform & 75\% Ethanol \\
\hline E. senticosus root & ESrW & ESrCh & ESrEt \\
E. senticosus fruit & ESfW & ESfCh & ESfEt \\
E. henryi root & EHrW & EHrCh & EHrEt \\
E. henryi fruit & EHfW & EHfCh & EHfEt \\
\hline
\end{tabular}

\section{Cage tests: Screening for the best method to obtain the Eleutherococcus extract}

\section{Honeybee lifespan}
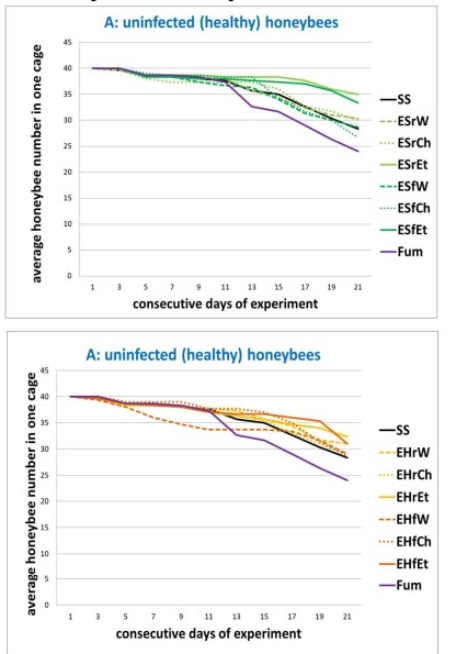

Food consumption

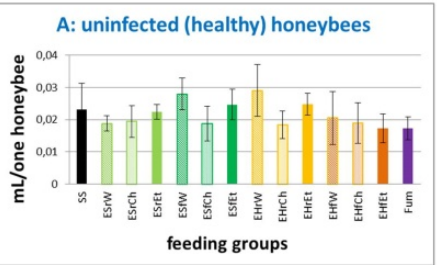

\section{Nosemosis level}

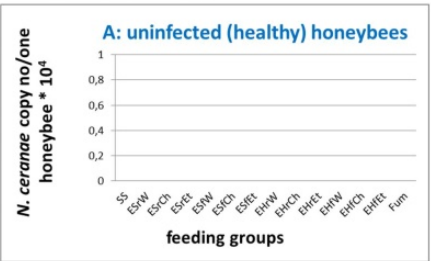

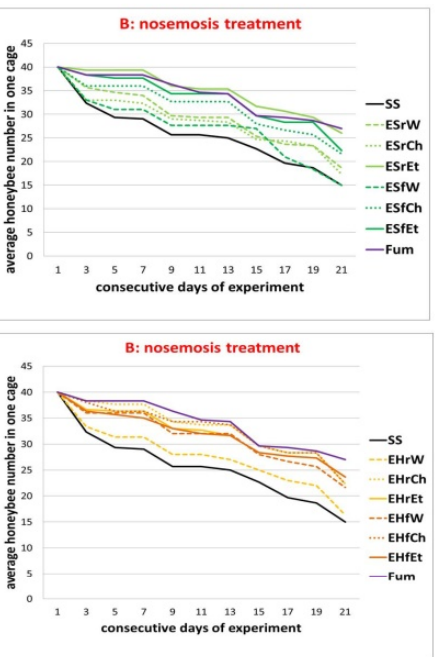
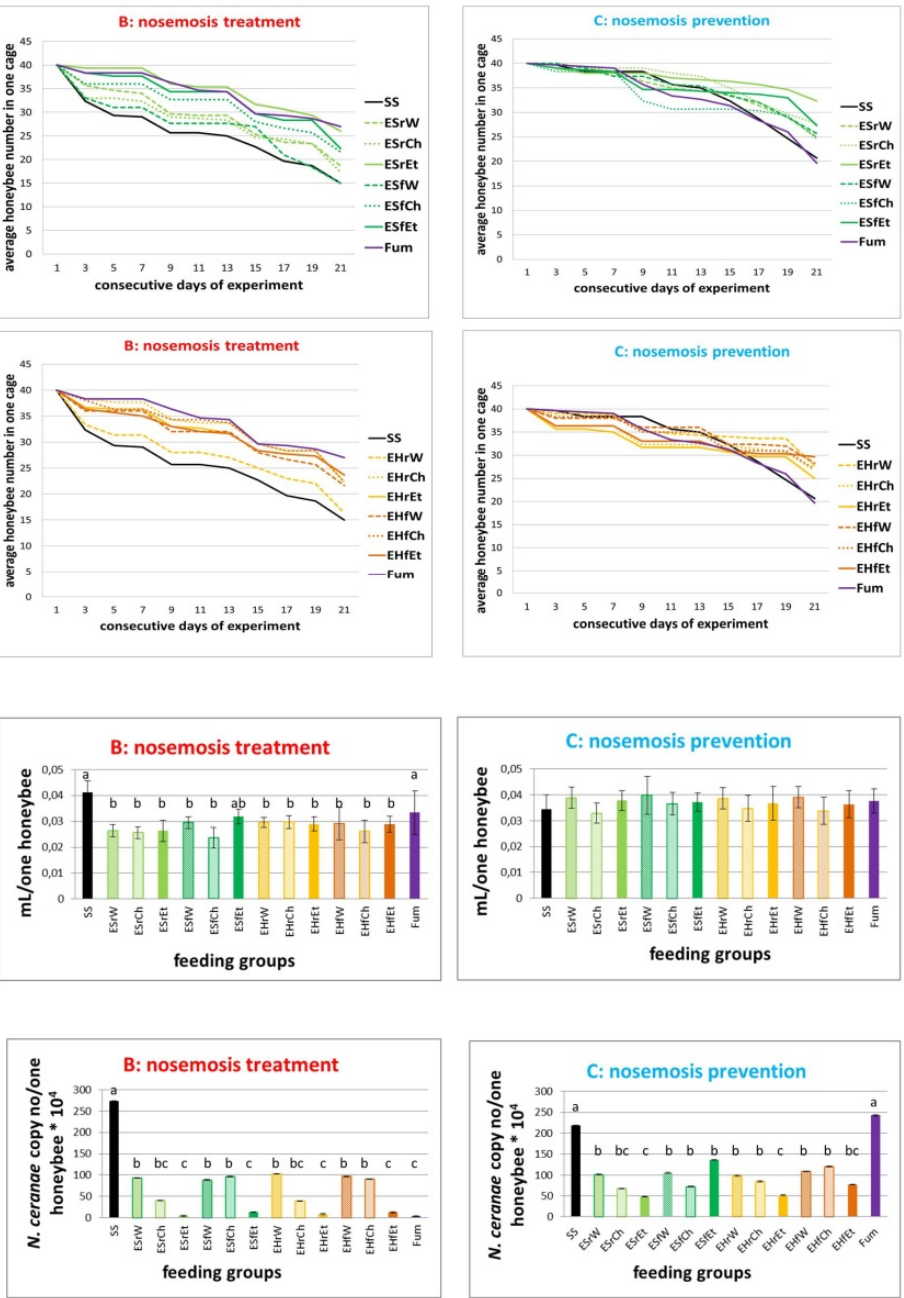

Figure 2. Results of cage tests: Screening for the best method of obtaining the Eleutherococcus extract. Data illustrated honeybee lifespan, food consumption and levels of nosemosis in all three variants of 
experiments conducted, i.e., (A) uninfected honeybees, (B) treatment of nosemosis and (C) prevention of nosemosis were compared. Lowercase letters $(a, b, c)$ indicate significant differences between the group fed pure sucrose syrup without extracts (SS) and the groups fed with additions of extracts (at least $p \leq 0.05$ for the honeybee lifespan, $p \leq 0.01$ for food consumption and $p \leq 0.005$ for level of nosemosis) (ANOVA, Tukey test). Error bars denote a confidence interval (CI). Laboratory extracts of E. senticosus (ES) and E. henryi (EH) were obtained using three different methods (water, W, chloroform, $\mathrm{Ch}$, and ethanol, Et, extraction) from these plants' roots and fruits (Table 2). 14 feeding groups (acronyms are defined in Supplementary Materials Table S2), i.e., (1) SS (control, pure sucrose syrup), (2) ESrW, (3) ESrCh, (4) ESrEt, (5) ESfW, (6) ESfCh, (7) ESfEt, (8) EHrW, (9) EHrCh, (10) EHrEt, (11) EHfW, (12) EHfCh, (13) EHfEt, (14) Fum (positive control in the treatment of nosemosis, fumagillin). All pure laboratory extracts were added in the concentration of $0.4 \mathrm{mg} / \mathrm{mL}$ to compare three different methods of obtaining extracts.

\subsubsection{Results of Cage Tests: Screening for the Best Eleutherococcus Dose}

Laboratory E. senticosus ethanol root extract was added to the sucrose solution to the final concentrations of $0.05 \mathrm{mg} / \mathrm{mL}, 0.2 \mathrm{mg} / \mathrm{mL}, 0.4 \mathrm{mg} / \mathrm{mL}, 0.9 \mathrm{mg} / \mathrm{mL}$ and $1.5 \mathrm{mg} / \mathrm{mL}$ (Figure 3 , acronyms are defined in Supplementary Materials Table S3). E. senticossus in $0.4 \mathrm{mg} / \mathrm{mL}$ concentration visibly prolonged bee lifespan, strongly reduced the level of nosemosis and was eagerly consumed in variant A. Although E. senticossus in $1.5 \mathrm{mg} / \mathrm{mL}$ concentration reduced the level of nosemosis, it also decreased honeybee lifespan, and was very reluctantly consumed. Increased mortality in the $1.5 \mathrm{mg} / \mathrm{mL}$ group could probably be associated with the extract's toxicity for honeybees. Further studies on pure substances should clarify this question. According to data from Supplementary Materials Table S4, the selected most effective concentration of $0.4 \mathrm{mg} / \mathrm{mL}$ E. senticosus extract responded to $5.76 \mu \mathrm{g} / \mathrm{mL}$ of eleutheroside B, $2.56 \mu \mathrm{g} / \mathrm{mL}$ of eleutheroside $\mathrm{E}$ and $0.068 \mu \mathrm{g} / \mathrm{mL}$ of naringenin.

Taking into account that the average syrup consumption for $0.4 \mathrm{mg} / \mathrm{mL}$ E. senticosus extract supplementation was $0.021395( \pm 0.006838), 0.022005( \pm 0.009454)$ and $0.021217( \pm 0.009464) \mathrm{mL} /$ honeybee per day in the groups A, B and C respectively (Figure 3), the average sucrose solution consumption was equal to $0.02154( \pm 0.008585) \mathrm{mL} /$ honeybee per day. Therefore, during 6 days of extract supplementation, each honeybee received c.a. $0.744 \mu \mathrm{g}$ of eleutheroside B, $0.331 \mu \mathrm{g}$ of eleutheroside E and $0.009 \mu \mathrm{g}$ of naringenin. The optimum dose calculated per one honeybee/day was $0.124 \mu \mathrm{g}$ of eleutheroside $B$, $0.055 \mu \mathrm{g}$ of eleutheroside $\mathrm{E}$ and $0.001 \mu \mathrm{g}$ of naringenin.

The toxic effect observed for the $1.5 \mathrm{mg} / \mathrm{mL}$ E. senticosus extract responded to $21.6 \mu \mathrm{g} / \mathrm{mL}$ of eleutheroside $B, 9.6 \mu \mathrm{g} / \mathrm{mL}$ of eleutheroside $\mathrm{E}$ and $0.255 \mu \mathrm{g} / \mathrm{mL}$ of naringenin. The toxic effect of $1.5 \mathrm{mg} / \mathrm{mL}$ E. senticosus extract was clearly observed in the groups A (control, uninfected honeybees) and C (prevention of nosemosis), whereas in the group B (treatment of nosemosis), it was probably firstly covered by the curing effect of the extract treatment on the course of nosemosis (Figure 3). Nevertheless, the toxic effects of eleutherosides should be checked in further studies conducted on pure substances. Furthermore, other compounds also present in these plant extracts, such as, e.g., piperasines, chiisanoside or sessilines, should be checked as well, because their effects on honeybees are unknown.

Taking into account that the average syrup consumption for $1.5 \mathrm{mg} / \mathrm{mL}$ E. senticosus extract supplementation was $0.00927( \pm 0.002259), 0.01128( \pm 0.004732)$ and $0.00951( \pm 0.002207) \mathrm{mL} /$ honeybee per day in groups A, B and C respectively (Figure 3), the average sucrose solution consumption was equal to $0.01002( \pm 0.003066) \mathrm{mL} /$ honeybee per day. Therefore, during 6 days of extract supplementation, each honeybee received c.a. $1.299 \mu \mathrm{g}$ of eleutheroside B, $0.577 \mu \mathrm{g}$ of eleutheroside E and $0.015 \mu \mathrm{g}$ of naringenin. The toxic dose calculated per one honeybee/day was $0.216 \mu \mathrm{g}$ of eleutheroside B, $0.096 \mu \mathrm{g}$ of eleutheroside $\mathrm{E}$ and $0.003 \mu \mathrm{g}$ of naringenin. Nevertheless, the toxic effects of eleutherosides should be checked in further studies conducted on pure substances.

Summarising, $0.4 \mathrm{mg} / \mathrm{mL}$ E. senticosus extract concentration was most beneficial in cage tests. Therefore, we chose this concentration for field apiary tests. However, in their natural environment, 
honeybees are not only fed supplements provided by beekeepers, but also forage on their natural floral resources. Consequently, we also picked higher E. senticosus extract concentration of $0.9 \mathrm{mg} / \mathrm{mL}$ for field studies, which was safe for honeybees and effective in the treatment of nosemosis during cage tests.

\section{Cage tests: Screening for the best Eleutherococcus dose}

\section{Honeybee lifespan}

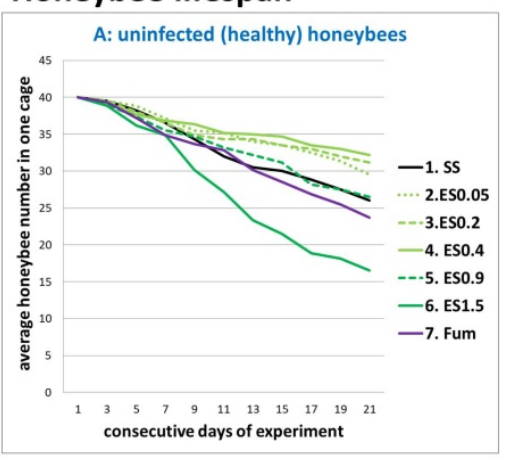

\section{Food consumption}

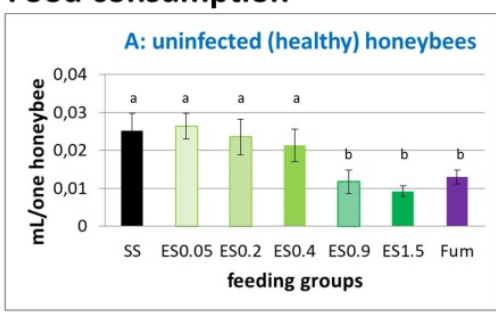

\section{Nosemosis level}
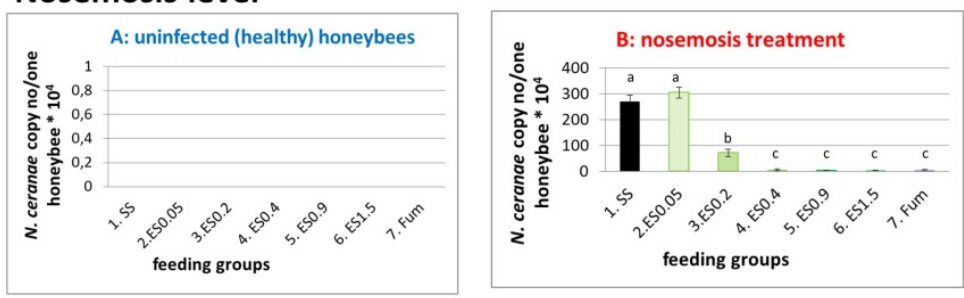

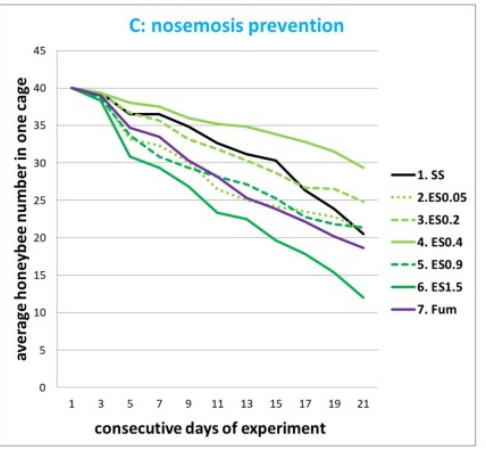

consecutive days of experimen

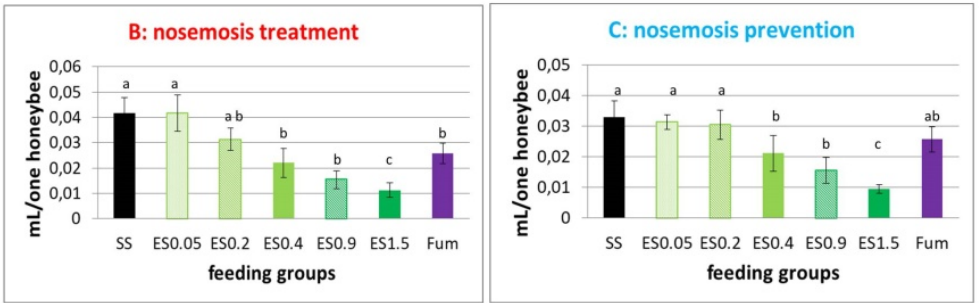

Figure 3. Results of cage tests: Screening for the best Eleutherococcus dose. Data illustrated honeybee lifespan, food consumption and the level of nosemosis in all three variants of conducted experiments, i.e., (A) uninfected honeybees, (B) treatment of nosemosis and (C) prevention of nosemosis were compared. Lowercase letters $(a, b, c)$ indicate significant differences between the group fed with pure sucrose syrup without extracts (SS) and the groups fed with additions of extracts (at least $p \leq 0.05$ for the honeybee lifespan, $p \leq 0.05$ for food consumption and $p \leq 0.01$ for level of nosemosis) (ANOVA, Tukey test). Error bars denote a confidence interval (CI). Feeding groups: E. senticosus ethanol root extract was added to the sucrose solution to the final concentrations of $0.05 \mathrm{mg} / \mathrm{mL}, 0.2 \mathrm{mg} / \mathrm{mL}$, $0.4 \mathrm{mg} / \mathrm{mL}, 0.9 \mathrm{mg} / \mathrm{mL}$ and $1.5 \mathrm{mg} / \mathrm{mL}$. Uninfected and Nosema-infected honeybees from A, B and $\mathrm{C}$ variants were divided into 14 feeding groups (acronyms are defined in Supplementary Materials Table S3): (1. SS) control, pure sucrose syrup without extracts, (2. ES0.05) sucrose syrup supplemented with $0.05 \mathrm{mg} / \mathrm{mL}$ E. senticosus extract, (3. ES0.2) sucrose syrup supplemented with $0.2 \mathrm{mg} / \mathrm{mL}$ E. senticosus extract, (4. ES0.4) sucrose syrup supplemented with $0.4 \mathrm{mg} / \mathrm{mL}$ E. senticosus extract, (5. ES0.9) sucrose syrup supplemented with $0.09 \mathrm{mg} / \mathrm{mL}$ E. senticosus extract, (6. ES1.5) sucrose syrup supplemented with $1.5 \mathrm{mg} / \mathrm{mL}$ E. senticosus extract, (7. Fum) fumagillin, positive control in the treatment of nosemosis. 


\subsection{Additional Tests}

\subsubsection{Results of Field Tests}

15 healthy colonies with similar strength and 15 medium infected colonies with the similar infestation level between $140.77 \times 10^{4}( \pm 24.86)$ and $166.4 \times 10^{4}( \pm 23.94)$ Nosema copy number/bee were selected for the experiment. Differences among selected colonies were not significant $(p>0.05)$. Colonies in each apiary were divided into 6 groups, i.e., (F1) 5 colonies as control, an untreated group with healthy honeybees, (F2) 5 colonies with healthy honeybees fed with E. senticosus extract in the concentration of $0.4 \mathrm{mg} / \mathrm{mL}$, (F3) 5 colonies with healthy honeybees fed with E. senticosus extract in the concentration of $0.9 \mathrm{mg} / \mathrm{mL}$, (F4) 5 colonies with the control, untreated group with Nosema-infected honeybees, (F5) 5 colonies with Nosema-infected honeybees fed with E. senticosus extract in the concentration of $0.4 \mathrm{mg} / \mathrm{mL}$ and (F6) 5 colonies with Nosema-infected honeybees fed with E. senticosus extract in the concentration of $0.9 \mathrm{mg} / \mathrm{mL}$.

Honeybee winter debris weight was similar in 2018 in all experimental colonies, but in 2019, there were significant differences; in the F4 group (Nosema-infected honeybees untreated with E. senticosus extract), winter debris was even two times higher than in other groups of infected honeybees fed with E. senticosus extracts. After the first season of treating honeybee colonies with E. senticosus extract, the level of nosemosis in treated groups was strongly reduced, and in colonies from F5-F6 groups fed with E. senticosus extracts, it was even 57 times lower than in the control group with Nosema-infected honeybees untreated with E. senticosus extract. The E. senticosus extract in the concentration of $0.9 \mathrm{mg} / \mathrm{mL}$ was more effective during the treatment of nosemosis in the first season $(p<0.01)$. During the second treatment season, the differences between colonies treated with 0.4 and $0.9 \mathrm{mg} / \mathrm{mL}$ extract concentrations blurred and were not relevant $(p>0.5)$; at the same time, there were no differences between these groups in weight of winter debris (Figure 4).

Additional tests: Field tests
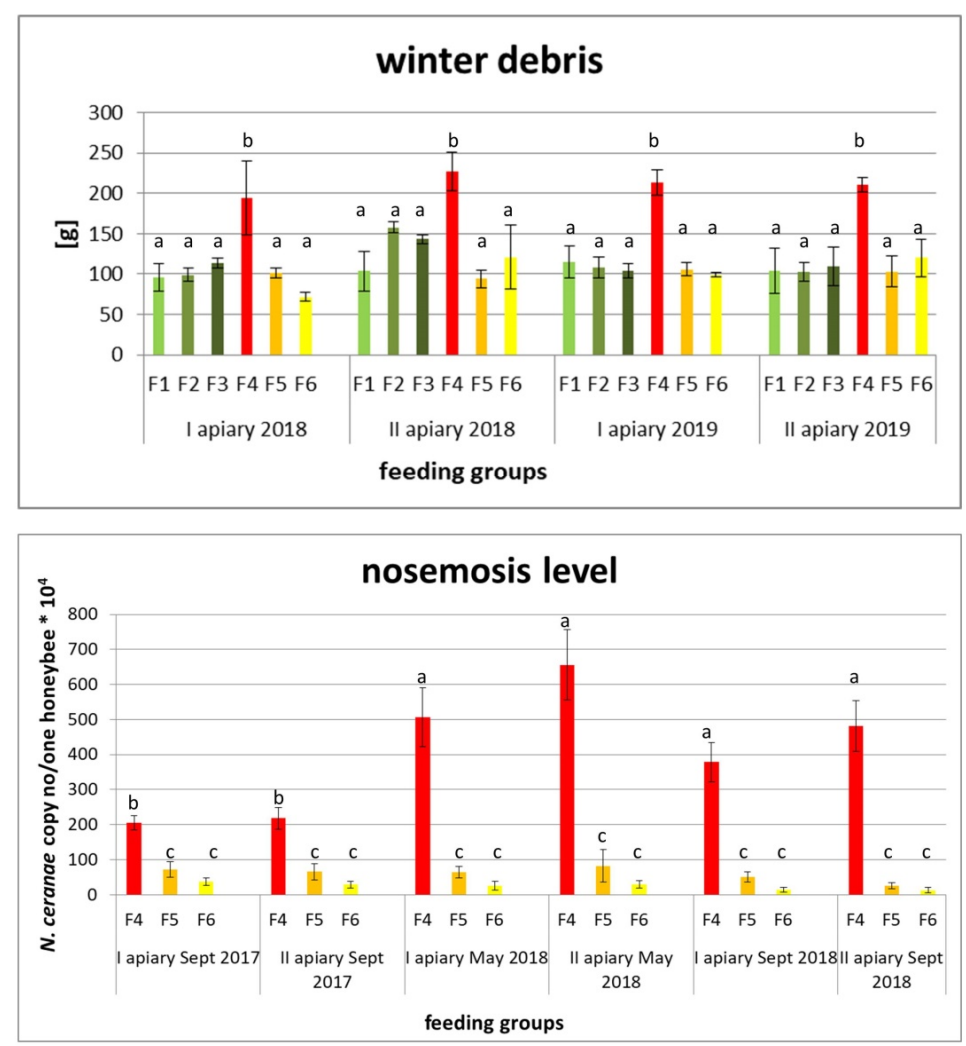

Figure 4. Results of additional tests: Field tests. Data illustrated winter debris and average levels of nosemosis in honeybee colonies fed with pure sucrose solution without extraxts (F1 and F4 groups with 
uninfected and Nosema-infected colonies, respectively), with E. senticosus extract in the concentration of $0.4 \mathrm{mg} / \mathrm{mL}$ (F2 and F5 groups with uninfected and Nosema-infected colonies, respectively) and with E. senticosus extract in the concentration of $0.9 \mathrm{mg} / \mathrm{mL}$ (F3 and F6 groups with uninfected and Nosema-infected colonies, respectively). Error bars denote a confidence interval (CI). In each apiary, colonies were divided into 6 groups, i.e., (F1) 5 colonies as control, untreated group with healthy honeybees, (F2) 5 colonies with healthy honeybees fed with E. senticosus extract in the concentration of $0.4 \mathrm{mg} / \mathrm{mL}$, (F3) 5 colonies with healthy honeybees fed with E. senticosus extract in the concentration of $0.9 \mathrm{mg} / \mathrm{mL}$, (F4) 5 untreated colonies with Nosema-infected honeybees, (F5) 5 colonies with Nosema-infected honeybees fed with E. senticosus extract in the concentration of $0.4 \mathrm{mg} / \mathrm{mL}$ and (F6) 5 colonies with Nosema-infected honeybees fed with E. senticosus extract in the concentration of $0.9 \mathrm{mg} / \mathrm{mL}$.

2.2.2. Results of LIVE/DEAD Tests and Nosema Spore Cell Wall Analysis under Scanning Electron Microscopy (SEM)

The pre-treatment of N. ceranae spores with Eleutherococcus extracts had no effect on spores' viability, their cell wall sculpture (Supplementary Figure S1) and furthermore, their ability to infect honeybees.

The pre-treatment of $N$. ceranae spores with E. senticosus in concentrations 0.4 and $0.9 \mathrm{mg} / \mathrm{mL}$ had no impact on spores' viability observed after using dyes: SYTO 9 and propidium iodide, nor the ability to infect honeybees ( $\mathrm{n}=300 ; p>0.5$, analysis of variance (ANOVA) and Tukey test). The number of live spores in the control was $67.56 \times 10^{4}( \pm 3.973)$, after pre-treatment with E. senticosus in concentrations of $0.4 \mathrm{mg} / \mathrm{mL}$, it was $66.81 \times 10^{4}( \pm 5.355)$ and after pre-treatment with $E$. senticosus in concentrations of $0.9 \mathrm{mg} / \mathrm{mL}$, it was $67.14 \times 10^{4}( \pm 5.731)$.

Spore suspensions after extract pre-treatment were added to the 1:1 w:v sucrose solution to feed honeybees. In all three groups (control, spore suspensions after pre-treatment with E. senticosus in concentrations $0.4 \mathrm{mg} / \mathrm{mL}$ and in the concentration of $0.9 \mathrm{mg} / \mathrm{mL}$ ), the sucrose solution was consumed at similar levels, i.e., observed daily consumption per one honeybee in the control was $0.0391 \mu \mathrm{L}$ $( \pm 0.00950)$, in concentrations $0.4 \mathrm{mg} / \mathrm{mL}$ it was $0.0390 \mu \mathrm{L}( \pm 0.01041)$ and in concentrations of $0.9 \mathrm{mg} / \mathrm{mL}$ it was $0.0413 \mu \mathrm{L}( \pm 0.01088)$. The level of nosemosis calculated using qPCR (quantitative polymerase chain reaction) was similar in all three groups $(p>0.5)$ and in the control it was equal to $250.9 \times 10^{4}$ $( \pm 30.27) N$. ceranae copies, in concentrations of $0.4 \mathrm{mg} / \mathrm{mL}$ it was $283.9( \pm 15.60)$ and in concentrations of $0.9 \mathrm{mg} / \mathrm{mL}$ it was $261.0 \times 10^{4}( \pm 46.2) \mathrm{N}$. ceranae copies. Honeybee mortality was similar $(p>0.5)$ in all three experimental groups.

Summing up, there must be other mechanisms that cause administration of extracts to honeybees to lengthen honeybee lifespan and limit the development of nosemosis. We hypothesised that eleutherosides benefited the honeybee immune system. The effect of eleutherosides on honeybees should be checked in further studies to be conducted on pure substances.

\subsection{Phytochemical Analysis of the Extracts and Honey}

The biological analysis showed that the $75 \%$ ethanol extract from the roots of E. senticosus had the optimum effect on the course of nosemosis. This extract was studied for its chemical constituents, stability during the 2-year storage and its residue in honey. Eleutherosides are major components present in the E. senticosus roots and, according to European Pharmacopoeia, the total amount for the sum of eleutheroside B and E should not be lower than $0.08 \%$. In order to check which group of compounds may be responsible for an increase in the immune response in bees, all investigated extracts were subjected to HPLC-DAD (High-Performance Liquid Chromatography (HPLC) with a Diode-Array Detector) analysis to determine eleutherosides B and E and naringenin. The results obtained in this work showed eleutherosides B and $\mathrm{E}$ and naringenin to be present only in the roots of E. senticosus and E. henryi. The extract from the roots of E. senticosus contained eleutherosides B and E, 14.4 and $6.4 \mathrm{mg} / \mathrm{g}$ in dry extract respectively, and naringenin $0.17 \mathrm{mg} / \mathrm{g}$ in dry extract (Table 1). 
While, the roots of E. henryi contained eleutherosides B and E in the amount of 10.5 and $4.2 \mathrm{mg} / \mathrm{g}$ in dry extract, and respectively, naringenin $0.12 \mathrm{mg} / \mathrm{g}$ dry extract. Eleutheroside B was present in the majority of extracts, which may result from its higher polarity than eleutheroside E's and naringenin's. An exemplary chromatogram of eleutheroside B, E and naringenin in the extract is presented in Figure 5.

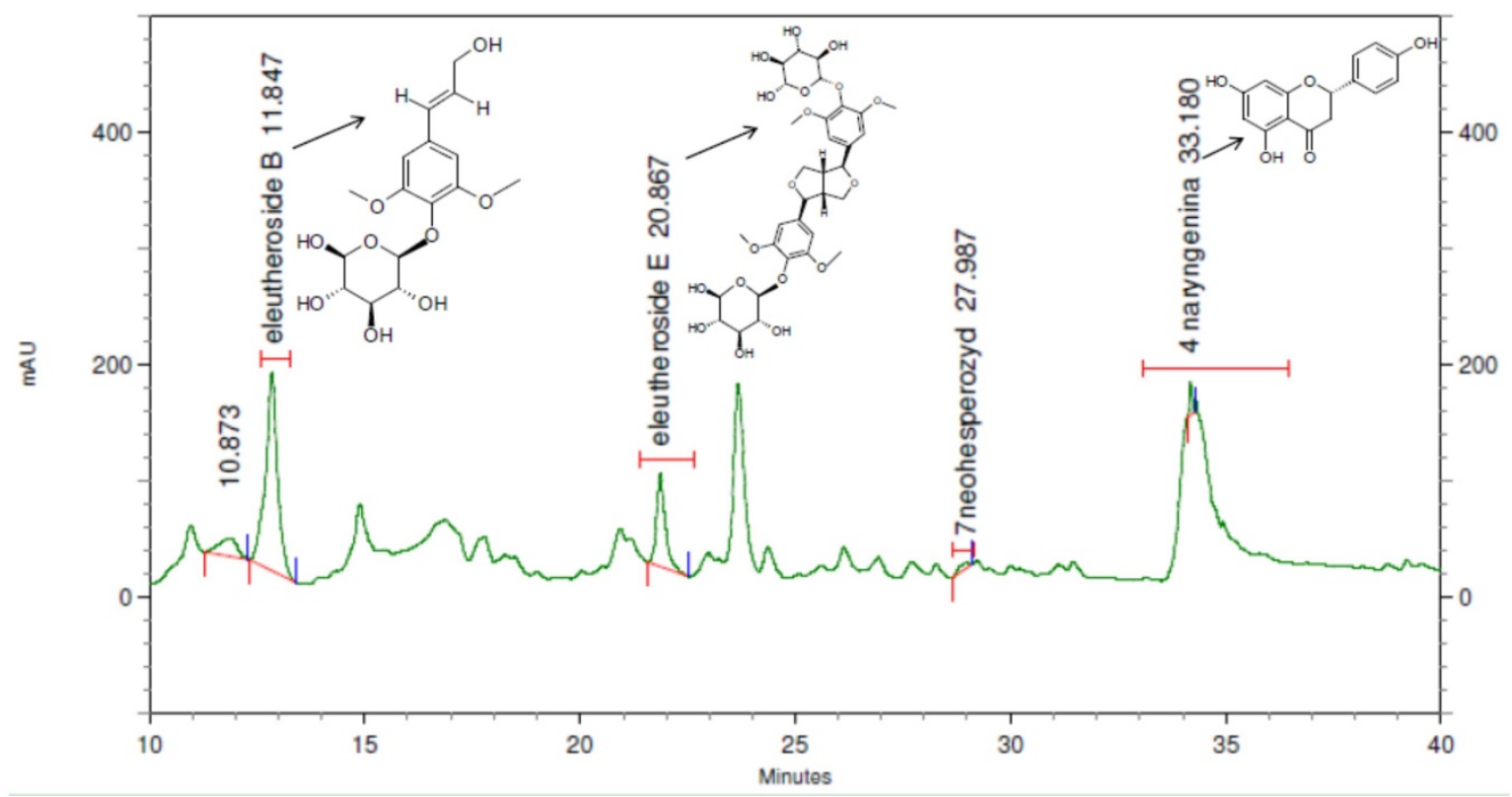

Figure 5. An exemplary chromatogram of the eleutheroside B, E and naringenin in the samples of freshly sourced extract.

The next step was to determine the eleutheroside content after 2 years of the extract's storage at $8^{\circ} \mathrm{C}$. There are no significant differences in eleutheroside $\mathrm{B}$ and $\mathrm{E}$ content between the freshly extracted dried roots and those after the 2-year storage (Supplementary Materials Table S4). Additionally, we did not detect eleutheroside $B$ and $E$ in honey made by honeybees whose diet was supplemented with E. senticosus extract (Supplementary Materials Figure S3).

\section{Discussion}

With the numbers of pollinators dramatically declining worldwide, the scientific community has been growing more and more concerned about the future of insects as fundamental elements of most terrestrial ecosystems. Therefore, we should look for preparations to support honeybee well-being. At present, many various types of synthetic substances are introduced into the environment, the accumulation of which may be harmful for insects. Thus, the search for a substance that would be beneficial for bees should be mainly based on natural substances. Furthermore, due to the fact that honeybee products are consumed by people, these substances must also be safe for people and their residues should not be present in honey or other bee products. Looking for substances that would increase bee resistance, we checked the effects of adaptogenic plants, which are defined as agents that support the ability to accommodate varying physical stresses, support health and prevent disease in both sick and healthy individuals through nonspecific effects and remain relatively safe and free of side effects. Adaptogenic plants selected for our study were: Eleutherococcus senticosus, Garcinia cambogia, Panax ginseng, Ginkgo biloba, Schisandra chinensis and Camellia sinensis. The E. senticosus root extract proved to be the most powerful.

Plant-based metabolites cover a very broad range of polarities, which means that merely a part of the plant's metabolites is present in the extract. Glycosides are well extracted with the $75 \%$ ethanol or methanol, sugars or phenolic acids may be extracted with water, and in turn, aglycons with non-polar 
solvents. The main group of the Eleutherococcus senticosus products on the market includes various extracts (ethanol, water). Cieśla et al. [42] studied the eleutherosides B and E content in the 75\% ethanol extracts from the dried roots of E. senticosus. The extract contained $0.77 \mathrm{mg}$ and $0.52 \mathrm{mg} / \mathrm{g}$ of the raw material dry weight, respectively [43]. According to Baczek et al. [44], the content of eleutheroside B and $\mathrm{E}$ in the dried roots of 4-year-old plants (methanol extract) was equal to 115.07 and $94.11 \mathrm{mg} / 100 \mathrm{~g}$, respectively. In another Baczek's study [45], the content of eleutherosides B and E in E. senticosus dried roots (methanol extract) depended on the plant's age (2,3,4 years) and the month of samples' collection (June, November). The results showed that the highest amount of eleutheroside B and E was produced in November by a 4-year-old plant and yielded in 103.57 and $105.14 \mathrm{mg} / 100 \mathrm{~g}$, for eleutheroside B and E, respectively. This is in agreement with Baczek's previous studies [46] and confirms a dependence of secondary metabolites' production on the plant's age, part and vegetation season in which plants were collected. The E. senticosus stem 50\% ethanol extract can contain $10.72 \mathrm{mg} / \mathrm{g}$ extract of eleutheroside E [47]. Eleutherosides and naringenin are the main active compounds of E. senticosus extract and act as immunostimulants [48,49]; therefore, their content in the extract should be exactly determined. In our study, E. senticosus root $75 \%$ ethanol extract in concentration of $0.4 \mathrm{mg} / \mathrm{mL}$ proved most effective and responded to $5.76 \mu \mathrm{g} / \mathrm{mL}$ of eleutheroside $\mathrm{B}, 2.56 \mu \mathrm{g} / \mathrm{mL}$ of eleutheroside $\mathrm{E}$ and $0.068 \mu \mathrm{g} / \mathrm{mL}$ of naringenin. The optimum doses calculated per one honeybee/day were: c.a. $0.124 \mu \mathrm{g}$ of eleutheroside $\mathrm{B}, 0.055 \mu \mathrm{g}$ of eleutheroside $\mathrm{E}$ and $0.001 \mu \mathrm{g}$ of naringenin. Nevertheless, the main therapeutic and prophylaxis effect against Nosema infection is probably connected only with eleutherosides as in other studies, naringenin from citrus fruit had a moderate effect on reducing Nosema spore loads and its main advantage was the extension of honeybees' lifetime [50].

In choosing proper medicine, the minimum effective dose and stability of active compounds are very important issues. Therefore, when administering any supplements, one should be very careful because "the dose makes the poison", as Paracelsus pointed out [51]. Honeybees are very fragile, and many phytochemicals showed toxic effects on their organisms, even in low concentrations, i.e., extracts from Allium sativum L., Artemisia absinthium L., Laurus nobilis L. [52-54] or clove oil and thymol [32]. Taking into account the weight of honeybees during our experiments, which was estimated at c.a. $128.4 \mathrm{mg}$, toxic doses calculated per one honeybee/day were: $0.216 \mu \mathrm{g}$ of eleutheroside B, $0.096 \mu \mathrm{g}$ of eleutheroside $\mathrm{E}$ and $0.003 \mu \mathrm{g}$ of naringenin. Therefore, we recommend using E. senticosus extract in the concentration of $0.4 \mathrm{mg} / \mathrm{mL}$ for the field application. The $0.9 \mathrm{mg} / \mathrm{mL}$ concentration was also safe in apiary tests (Figure 4) but during the long time treatment, there were not significant differences between the effects of these two concentrations. Consequently, we recommend the lowest effective dose, which was $0.4 \mathrm{mg} / \mathrm{mL}$ E. senticosus extract containing $5.76 \mu \mathrm{g} / \mathrm{mL}$ of eleutheroside B, $2.56 \mu \mathrm{g} / \mathrm{mL}$ of eleutheroside $\mathrm{E}$ and $0.07 \mu \mathrm{g} / \mathrm{mL}$ of naringenin for the use in apiaries in order to prevent the risk of toxic effects on honeybees observed at higher E. senticosus extract concentrations, which might be caused by the uncontrolled usage or arbitrary increase in the frequency of administration by the beekeepers exceeding recommended doses.

In the next step, the stability of extracts during the 2-year storage was evaluated in this study. There were no significant differences between freshly sourced extracts and those after 2-year storage (Supplementary Materials Table S4.). Previous studies by Załuski and Janeczko [55] revealed that the long-time storage of the Eleutherococcus samples did not affect their chemical composition and there were no significant differences in polyphenols and minerals content. In cage tests, we also checked the properties of the 2-year storage extract on honeybees infected with nosemosis and there were no significant differences between the effects of freshly sourced extract and the 2-year stored one (data not presented).

Assessing the residue of eleutherosides in the final product, honey is the most important factor from the application and the consumer safety point of view. No pictures characteristic for eleutherosides were observed in the chromatogram on the basis of the HPLC-DAD analysis, which indicates a lack of eleutherosides in honey (Supplementary Materials Figure S3). It is worth noting that eleutherosides are safe for humans and could even be a desirable constituent of honey. Such a combination could 
strengthen its nutritional and pro-health properties. Administration of the standardised E. senticosus products is important for people who suffer from heart diseases and take digoxin-based drugs. Some European manufacturers offer standardised herbal extracts fortified with extracts containing higher eleutherosides concentration. The analysis of eleutherosides is highly effective in the assessment of the E. senticosus-based products and should be the first step to take when products are imported into the EU.

Checking honeybees' food preferences for proposed food supplements, it is very important to estimate the efficiency of proposed preparations in supporting honeybee well-being. In our study, honeybees willingly ate the sucrose solution with the addition of extracts from: E. senticosus, G. cambogia, G. biloba and S. chinensis (Figure 1). The extract from P. ginseng and C. sinensis caused the sucrose solution to be unattractive and honeybees were reluctant to take it (Table 1, Figure 1). Other studies also indicated that the effect of therapeutic agents was strongly correlated with honeybee food preferences and a low consumption of products was probably the reason for the lack of their declared healing effect, as was proven for Nosestat ${ }^{\circledR}$, Phenyl salicylate and Vitafeed Gold ${ }^{\circledR}$ [56]. Our study also indicated honeybee food preference as the main factor for the therapeutic agents' healing effect.

Insects are complex organisms with sophisticated social behaviour, feeding preferences and complex immunity. Tauber et al. [57] recommended that we should look for natural products to treat honeybees. However, it is not only the combination of results from survival and disease development as Tauber et al. [57] claimed, but also honeybee feeding preferences that should be considered during potential honeybee medicament tests.

Due to the fact that the Nosema spore cell wall is not the target for E. senticosus extract effect (Supplementary Figure S1), as was the case with porphyrins [58], there must be a different explanation of its healing effect. E. senticosus extract decreased the level of nosemosis, both after the infection as a curing treatment and used in the prophylaxis (Figures 1-3, B: nosemosis treatment, C: nosemosis prevention). Hence, we hypothesise that $E$. senticosus extract effect is connected with its adaptogenic properties and provokes an adaptogenic effect in honeybees. The pharmacological assessment of adaptogens typically includes the evaluation of their stimulating, tonic and stress-protective effects. Here, we show for the first time such adaptogenic plant extracts' impact on invertebrates in honeybees stressed by nosemosis.

Insects and other invertebrates lack certain characteristics of the adaptive immune system, instead they rely on innate immune responses to defend against foreign microorganisms and mount several defence reactions, including the activation of prophenoloxidase (proPO) into its active form phenoloxidase (PO) [59,60]. In our earlier studies [61], we observed the increased level of PO in the hemolymph of infected honeybee treated with E. senticosus extracts. The level of PO in honeybee hemolymph was checked using standard, previously described procedures [62-64]. This observed PO increment was strongly correlated with the Nosema infection. PO was at a physiologically low level in the hemolymph of non-infected honeybees treated with E. senticosus extracts. However, after the infection, the hemolymph of honeybees treated with E. senticosus extracts had much higher amounts of PO in comparison to honeybees untreated with E. senticosus extracts. This increase in PO level is very interesting due to the fact that insect PO in hemolymph is inhibited after the injection of fungal spores [65,66]. In our study [61], we observed that honeybees fed with E. senticosus extracts and infected with Nosema spp. spores had higher PO levels than those in control groups of Nosema-infected insects fed with the pure sucrose solution. Therefore, the effect of the E. senticosus extracts on honeybee had a similar adaptogenic response as on other animals, including humans [67,68]. We additionally hypothesised that these adaptogenic properties were connected with eleutherosides, the active compounds found exclusively in plants from the Eleutherococcus genus and undetected in other studied plant extracts. These active compounds are very stable in plant extracts and can be found in similar amounts even after two years from extraction (Supplementary Materials Table S4). In honeybees treated with such 2-year extracts, nosemosis level decreased comparably to the group of honeybees treated with freshly sourced extracts. 
This adaptogenic effect of E. senticosus extract was also observed in our field studies (4.13.1. Field tests, Figure 4). Honeybee colonies which had been administered E. senticosus extract twice a year had lower winter debris and had lower levels of nosemosis than the colonies which were left untreated (Figure 4). Although there were natural, seasonal fluctuations in levels of nosemosis connected with its progress in honeybee colonies in temperate zones [17,69-71], colonies treated with E. senticosus extract always had lower Nosema load than colonies left untreated. These studies could be the basis for composing new functional honeybee food. Such food additives can strengthen honeybee colonies' immunity and prevent colony losses.

Natural products, such as herb extract, provide promising candidates for 'bee medicines' or for a safe prophylaxis [57]. Eleutherococcus senticosus extract is rich in many secondary metabolites with proven adaptogenic properties $[67,72]$. The pollinator fidelity hypothesis suggested that so-called "toxic nectar" is analogous to other floral structures that require specialisation of pollinators $[24,73,74]$. Honeybees taking such herb nectar might self-heal slightly or weakly infected colonies $[15,17]$. We bring out this hypothesis here because nectars rich in specific secondary compounds can decidedly benefit honeybees. Eleutherococcus senticosus, and its active compounds, eleutherosides, are considered the most powerful adaptogens, in the pool of all extracts that were selected for screening, for supporting immunity and improving resistance of honeybees.

\section{Methods}

\subsection{Standards and Reagents}

Ethanol was obtained from POCH (Polish Chemicals Reagents, Lublin, Poland). The standards of eleutheroside $B \geq 98.0 \%$ (HPLC), eleutheroside $E \geq 98.0 \%$ (HPLC) and naringenin $\geq 98.0 \%$ (HPLC), were obtained from Sigma-Adrich. LC-grade methanol (Methanol gradient grade for Liquid Chromatography) was purchased from J.T. Baker (Phillipsburg, NJ, USA). Ultrapure water was prepared using the Millipore Direct-Q3 purification system (Bedford, MA, USA). All other reagents were of analytical grade.

\subsection{Plant Material}

The roots and fruits of E. senticosus (Rupr. et Maxim.) Maxim. and E. henryi Oliv. were collected at the arboretum in Rogów (Poland) in October 2015 (voucher specimen numbers: ES01/2015, EH02/2015). All plant samples were deposited at the Department of Pharmaceutical Botany and Pharmacognosy, Nicolaus Copernicus University, Poland. The growth conditions were as follows: geographic data $51^{\circ} 49^{\prime} \mathrm{N}$ and $19^{\circ} 53^{\prime} \mathrm{E}$, the average, long-term temperature $-20.1^{\circ} \mathrm{C}$, the $6 \mathrm{bth}$ sub-climate (according to the United States Department of Agriculture Frost Hardiness Zones), and the second zone according to the Kórnik's category [75]. The plants were grown on the acidic, luvic and sandy soils [75]. Plant materials' identity was evaluated morphologically [76] and by HPLC-PDA analysis (see Section 4.6.), in comparison with reference substances (eleutherosides B and E).

\subsection{Dried Material Extraction with $75 \%$ Ethanol}

The air-dried roots and fruits ( $5 \mathrm{~g}$ each) were soaked in $50 \mathrm{~mL} 75 \%$ ethanol for $24 \mathrm{~h}$. Next, the samples were subjected to triple UAE-type extraction (Ultrasonic-Assisted Extraction, ultrasonic bath, Polsonic, Warsaw, Poland) using $1 \times 50 \mathrm{~mL}$ and $2 \times 25 \mathrm{~mL}$ of $75 \%$ ethanol. The extraction was performed at room temperature for $15 \mathrm{~min}$ for each cycle. Finally, $100 \mathrm{~mL}$ of each extract was obtained. The solvents were dried with an evaporator under vacuum conditions at $45{ }^{\circ} \mathrm{C}$ and subjected to lyophilisation.

\subsection{Dried Material Extraction with Chloroform}

The roots and fruits were extracted using chloroform in the same way as the extraction with $75 \%$ ethanol. 


\subsection{Infusion Preparation}

The infusion was prepared by adding $50 \mathrm{~mL}$ of distilled water $\left(95^{\circ} \mathrm{C}\right)$ to $5 \mathrm{~g}$ of the fruits or roots. The infusions were brewed for $15 \mathrm{~min}$ and were then filtered over Whatman No. 1 paper. The aqueous extracts were frozen and lyophilised.

\subsection{Phytochemical Analysis of the Extracts and Honey}

For this purpose, the Agilent 1200 Series HPLC system (Agilent Technologies, Santa Clara, CA, USA) was used equipped with a binary gradient solvent pump, a degasser and an autosampler. The separation of the analytes was carried out on the Zorbax Eclipse XDB-C18 column $(4.6 \times 150 \mathrm{~mm}$, $5 \mu \mathrm{m}$ particle size; Agilent Technologies, Santa Clara, CA, USA) maintained at $25{ }^{\circ} \mathrm{C}$, using $3 \mu \mathrm{L}$ injections and the flow rate was $1 \mathrm{~mL} / \mathrm{min}$. The solvents used were water containing $5 \% \mathrm{ACN}$ (Acetonitrile solvent A) and water containing 60\% ACN (solvent B). The following gradient elution program at the flow rate of $370 \mu \mathrm{L} \mathrm{m^{-1 }}$ was applied: 0-5 min, 97\% A-3\% B; 6-30 min, 60\% A-40\% B; 31-45 $\mathrm{min}, 5 \% \mathrm{~B}-95 \% \mathrm{~A} ; 45.1-60 \mathrm{~min}, 97 \%$ A-3\% B. UV detection was conducted at $220 \mathrm{~nm}$. Triplicate injections were made for each standard solution and sample. A stock solution $(0.5 \mathrm{mg} / 0.5 \mathrm{~mL})$ of each eleutherosides B and E and naringenin was prepared in 75\% ethanol. Analytes' content was determined from the corresponding calibration curves. The calibration functions of the eleutherosides $B$ and $\mathrm{E}$ and naringenin were calculated using the peak area, concentration and mean values. There were three measurements for each concentration $(0.0010,0.0025,0.010,0.1 \mathrm{mg} / \mathrm{mL})$. Linearity ranges for calibration curves were specified (1-100 $\mu \mathrm{g} / \mathrm{mL})$, and a correlation coefficient of 0.999 (R2), respectively. (Supplementary Materials Table S4).

\subsection{Phytochemical Analysis of the Extracts: Stability of the Extracts in Time-HPLC-DAD Conditions of Eleutheroside $B$ and $E$ and Naringenin}

The HPLC-DAD analysis was performed according to the method described in Section 4.6. A fresh extract and an extract after 2 years of storage at $8{ }^{\circ} \mathrm{C}$ were studied.

\subsection{Phytochemical Analysis of the Honey: Eleutherococcus Extract Residues in Honey-HPLC-DAD of Eleutheroside $B$ and $E$ and Naringenin}

The HPLC-DAD analysis was performed according to the method described in Section 4.6. Honey samples were collected from 15 beehives and extracted using the liquid-liquid extraction. In brief, $1 \mathrm{~g}$ of honey was dissolved in $20 \mathrm{~mL}$ of distilled water (left for $24 \mathrm{~h}$, in a refrigerator). Next, the liquid-liquid extraction was performed using $5 \times 20 \mathrm{~mL}$ of ethyl acetate. Ethyl acetate layers were evaporated, and the residues were used in HPLC-DAD analysis.

\subsection{Animals, Cage and Field Tests}

Honeybees, Apis mellifera L., were maintained with standard beekeeping management methods

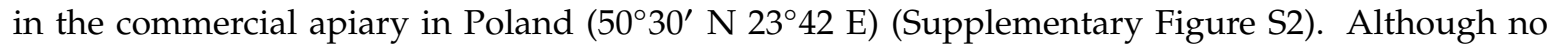
permission is needed to administer experiments on insects, our research was planned in a way that reduced the number of honeybees to the minimum necessary for the proper conduction of these experiments. Honeybee samples left after conducting experiments are stored at the Department of Immunobiology UMCS (Maria Curie-Sklodowska University in Lublin, Poland) deposition.

\subsection{Cage Tests: The Scheme of Administered Experiments}

Cage tests were performed on Apis mellifera L. worker bees. After emerging, honeybees were kept under laboratory conditions $\left(30{ }^{\circ} \mathrm{C}\right.$; Humidity $\left.=65 \%\right)$ in wooden cages. In all experiments, honeybees were fed with a daily solution of 1:1 weight/volume sucrose: $\mathrm{dH}_{2} \mathrm{O}$ solution supplemented with extracts or/and other substances. The control honeybees were fed with a pure sucrose solution. 
Emerging honeybees were divided randomly into three treatments, " $\mathrm{A}$ ", " $\mathrm{B}$ " and " $\mathrm{C}$ " (Figure 6). Honeybees in treatment " $\mathrm{A}$ " (control, impact of extracts on uninfected honeybees' lifespan), served as a control and were not infected with $N$. ceranae. In treatment " $\mathrm{B}$ " (impact of extracts on the treatment of nosemosis), to check whether the supplementation of honeybee diets with extracts influences the course of nosemosis, firstly, honeybees were Nosema ceranae-infected, and after that, fed with a sucrose syrup, containing extracts. In treatment " $\mathrm{C}$ " (impact of extracts on the prevention of nosemosis), to check whether the supplementation of honeybee diets with extracts protects honeybees against nosemosis, firstly, honeybees were fed with a sucrose syrup supplemented with extracts, and after that, were infected with $N$. ceranae spores.

\section{A: uninfected (healthy) honeybees}

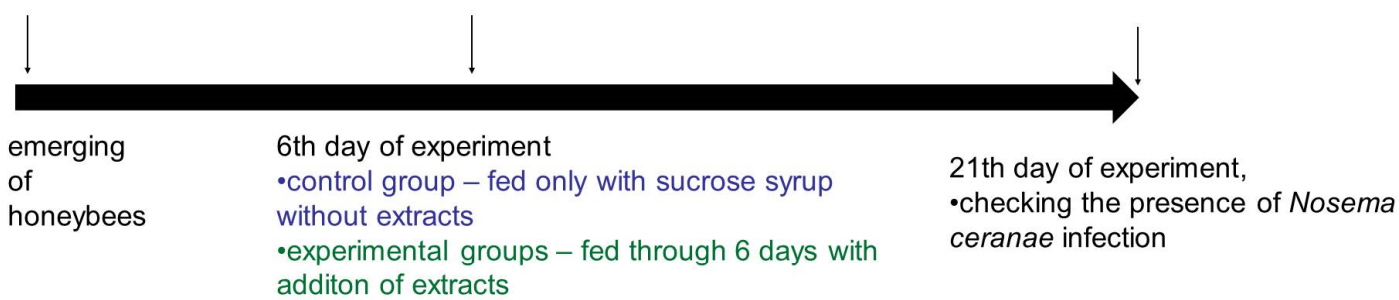

B: nosemosis treatment

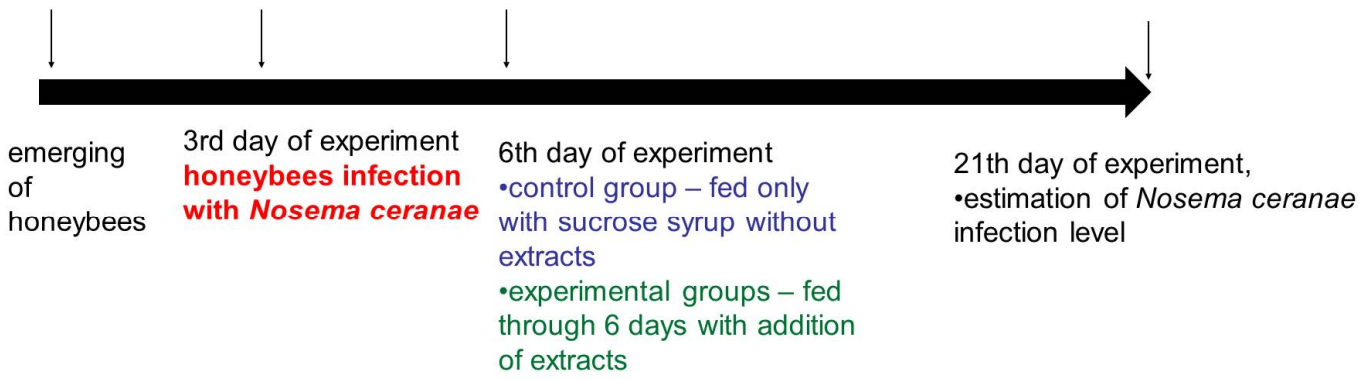

C: nosemosis prevention
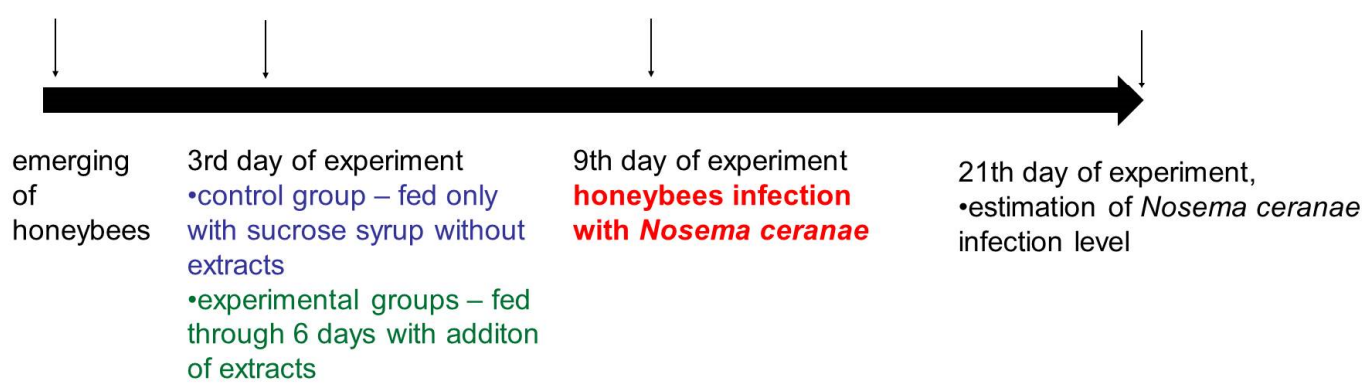

21 th day of experiment, -estimation of Nosema ceranae infection level

Figure 6. The scheme of administered experiments analysing the effect of extracts on honeybees which were uninfected and infected with Nosema ceranae.

To induce nosemosis, the honeybees were inoculated with a fresh solution containing $4 \times 10^{6}$ Nosema ceranae spores/mL, in the amount of $8 \mu \mathrm{L}$ per honeybee, and purified with classical methods according to the methodology described previously [77].

In each feeding group of cage tests, i.e., Sections 4.10.1-4.10.3, there were 3 cages settled by 40 honeybees in each (Table 3). 
Table 3. The cage tests' group sizes.

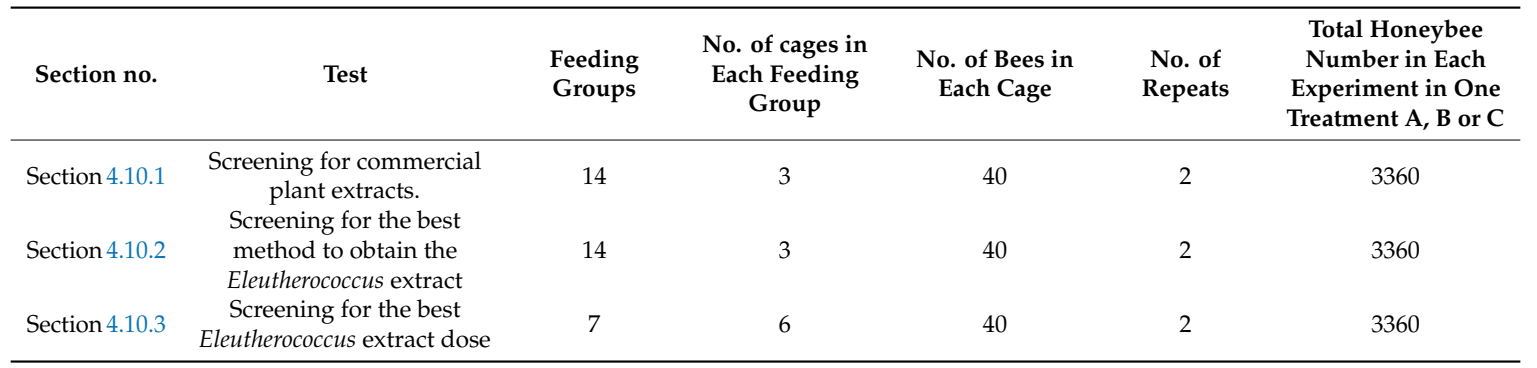

In all cage tests, dead bees were counted every day and the volume of eaten sucrose solution was estimated as the amount $(\mathrm{mL})$ of food taken from the syringe. Additionally, at the end of the experiments, the level of $N$. ceranae infection was estimated.

\subsubsection{Cage Tests: Screening of Commercial Plant Extracts}

Doses of the extracts, i.e., 0.2 and $1 \mathrm{mg}$ of active compound in $1 \mathrm{~mL}$ of the sugar syrup were estimated on the basis of the manufacturer's advice concerning an average daily dosage of these supplements, taking $130 \mathrm{mg}$ as an average honeybee weight. The average weight of honeybees was established after weighing 50 randomly chosen specimens used in the experiments, and was estimated at $128.4 \mathrm{mg}$.

Feeding groups: Commercial extracts were bought in a local herbal store. Commercial extract samples are available in the Department of Immunobiology UMCS resources (Lublin, Poland; $51^{\circ} 14^{\prime} 44^{\prime \prime} \mathrm{N} 22^{\circ} 32^{\prime} 26^{\prime \prime} \mathrm{E}$ ). Commercial extracts of Eleutherococcus senticosus (ES), Garcinia gummi-gutta (GG), Panax ginseng (PG), Schisandra chinensis (SC), Camellia sinensis (CS) and Ginkgo biloba (GB) were added to a sucrose syrup in two concentrations: $0.2 \mathrm{mg} / \mathrm{mL}$ (a) and $1 \mathrm{mg} / \mathrm{mL}$ (b), of declared concentration of an active compound. Uninfected and Nosema-infected honeybees from A, B and C variants (Figure 6) were divided into 14 feeding groups, i.e., (1) SS, (2) ESa, (3) ESb, (4) GGa, (5) GGb, (6) PGa, (7) PGb, (8) SCa, (9) SCb, (10) CSa, (11) CSb, (12) GBa, (13) GBb and (14) Fum, where (1) SS was 1:1 w:v 50\% sucrose solution, and (14) Fum, where $25 \mathrm{mg}$ bicyclohexylammonium fumagillin dissolved in 1 litre of sucrose solution, as in standard commercial use, was recommended.

\subsubsection{Cage Tests: Screening for the Best Method to Obtain the Eleutherococcus Extract}

Laboratory extracts of E. senticosus (ES) and E. henryi (EH) were obtained using three different methods (water, chloroform and ethanol extraction) from these plants' roots and fruits (Table 2).

Feeding groups: Uninfected and Nosema-infected honeybees from A, B and C variants were divided into 14 feeding groups, i.e., (1) SS, (2) ESrW, (3) ESrCh, (4) ESrEt, (5) ESfW, (6) ESfCh, (7) ESfEt, (8) EHrW, (9) EHrCh, (10) EHrEt, (11) EHfW, (12) EHfCh, (13) EHfEt and (14) Fum, where (1) SS was 1:1 w:v 50\% sucrose syrup, and (14) Fum, where $25 \mathrm{mg}$ bicyclohexylammonium fumagillin dissolved in 1 litre of the sucrose syrup, as in standard commercial use, was recommended. Pure laboratory extracts were added in the concentration of $0.4 \mathrm{mg} / \mathrm{mL}$. Fumagilline was used as a positive control due to its proven antymicrosporidial/antynosemosis activity.

\subsubsection{Cage Tests: Screening for the Best Eleutherococcus Dose}

E. senticosus ethanol root extract was added to the sucrose solution to the final concentrations of $0.05 \mathrm{mg} / \mathrm{mL}, 0.2 \mathrm{mg} / \mathrm{mL}, 0.4 \mathrm{mg} / \mathrm{mL}, 0.9 \mathrm{mg} / \mathrm{mL}$ and $1.5 \mathrm{mg} / \mathrm{mL}$. Uninfected and Nosema-infected honeybees from A, B and C variants were divided into 7 feeding groups, i.e., (1) SS, (2) ES0.05, (3) ES0.2, (4) ES0.4, (5) ES0.9, (6) ES1.5 and (7) Fum, where (1) SS was 1:1 w:v sucrose syrup, and (7) Fum, where $25 \mathrm{mg}$ bicyclohexylammonium fumagillin dissolved in 1 litre of the sucrose syrup, as in standard commercial use, was recommended. 


\subsection{Isolation of Total DNA from Honeybees and Molecular Detection of N. ceranae}

Total DNA from uninfected and N. ceranae-infected A. mellifera was isolated using the DNeasy ${ }^{\circledR}$ Plant Kit (Qiagen) according to the manufacturer's instruction. To identify N. ceranae DNA in the investigated samples, duplex polymerase chain reaction (PCR) was conducted with primers: 321-APIS and 218-MITOC primers [76] in a $25 \mu \mathrm{L}$ reaction mixture of the QIAGEN Taq PCR Core Kit (QIAGEN Inc.) containing $2.5 \mu \mathrm{L}$ PCR buffer $5 \mu \mathrm{L}$ Q solution, $0.1 \mathrm{mM}$ dNTP (deoxynucleoside triphosphate) mixture, $0.7 \mathrm{U}$ Taq DNA polymerase, $0.2 \mu \mathrm{M}$ of each forward and reverse primers, approximately $0.15 \mu \mathrm{g}$ of DNA template and $\mathrm{ddH}_{2} \mathrm{O}$ to a final reaction volume of $25 \mu \mathrm{L}$. For DNA amplification, the following PCR cycling conditions were used: $1 \mathrm{~min}$ at $94{ }^{\circ} \mathrm{C}, 1 \mathrm{~min}$ at $61.8^{\circ} \mathrm{C}$, and $1 \mathrm{~min}$ at $72{ }^{\circ} \mathrm{C}$, repeated for 30 cycles, and $10 \mathrm{~min}$ at $72{ }^{\circ} \mathrm{C}$.

\subsection{Estimation of the Level of Nosemosis Level}

Standard Nosema spp. spore counting: Samples were prepared from every group in two repeats to count $N$. ceranae spores. For one sample, 10 (cage tests) or 50 (field tests) honeybee abdomens were ground in $10 \mathrm{~mL}$ of sterile, distilled water and the number of Nosema spores was counted according to standard methods [77-80] using a haemocytometer and the Olympus BX61 light microscope. Furthermore, each sample was observed under bright field and differential interference contrast (DIC) to a proper differentiation of $N$. ceranae spores from other remains present in honeybees' homogenates.

Real-time PCR for relative quantification $N$. cearanae was performed in accordance with the guidelines proposed in previous studies [77,80-82]. DNA was extracted from pooled whole abdomens of 5 bees (cage tests) or 50 bees (field tests). Samples were homogenised with liquid nitrogen, mortar and pestle. Pulverised abdomens were transferred to a microfuge tube, lysis solution was added and protocol run according to the manufacturer's instructions for DNeasy ${ }^{\circledR}$ Plant Kit (Qiagen). A qPCR analysis was performed with TOptical Gradient 96 (Biometra) using primer pairs specific for the 16SSU rDNA (ribosomal DNA) region for N. ceranae and Apis mellifera $\beta$-actin according to Coplay and Jabaji [18], Chen et al. [83] and Chen et al. [84], i.e., NceranaeF 5-CGGATAAAAGAGTCCGTTACC-3, NceranaeR 5-TGAGCAGGGTTCTAGGGAT-3, NcerProbe 5-5HEXCGTTACCCTTCGGGGAATCTTC3IABkFQ/-3, ActinF 5-AGGAATGGAAGCTTG CGGTA-3, ActinR 5-AATTTTCATGGTGGATGGTGC-3, ActinProbe 5-56FAMATGCCAACACTGTC CTTTCTGGAGGTA3IABkFQ/-3, resulting in respective amplified products of 250 and $181 \mathrm{bp}$. Each N. ceranae and Apis mellifera actin amplification mixture was prepared according to Coplay and Jabaji [18]. The nucleic acid of N. cearanae levels were quantified in all samples and each well in the PCR plate was loaded with $50 \mathrm{ng}$ of DNA, all samples were run in triplicate technical runs. Standard curves and no template controls were run with each plate. Standard curve quantification was used to convert the resulting cycle threshold $\left(\mathrm{C}_{\mathrm{T}}\right)$ values to the number of copies of $N$. ceranae present in each sample. Serial dilutions using purified PCR products with known concentrations from $1 \times 10^{9}$ to $1 \times 10^{2}$ copies/ $\mu \mathrm{L}$ were used to prepare the standard curve. Positive and no template controls were run with each plate. The products of the amplifications were separated on $2 \%$ agarose gel to exclude the presence of primer-dimer structures and non-specific products. The coefficient of correlation values was calculated for each sample to ensure the repeatability of amplicons. The copy number was expressed as the average $N$. ceranae copy number per bee.

\subsection{Additional Tests}

\subsubsection{Field Tests}

Field tests were conducted in duplicate during two years in two commercial apiaries in Poland with the temperate continental climate, i.e., summers with average temperatures between 18 and $30{ }^{\circ} \mathrm{C}$ (i.e., 64.4 and $86.0 \mathrm{~F}$ ) and winters, with average temperatures between -10 and $3{ }^{\circ} \mathrm{C}$ (i.e., 14.0 and 37.4 F). Each commercial apiary maintained more than 120 colonies, and for the purpose of the research, 30 colonies were chosen from each apiary. In the spring (March 2017), dead worker 
honeybees (winter debris) were sampled from hive bottom-drawers in order to select colonies for field tests. The worker honeybees were collected separately from each colony and examined for the presence of Nosema spp. spores. For this purpose, 50 worker-bees from each colony were collected and analysed by optical microscopy $[79,80]$. In this way, colonies were divided into healthy (non-infected) and infected with Nosema spp. Colonies in which Nosema spp. spores were found were put in a secluded place and no nosemosis treatment was administered. The health status of selected colonies was confirmed using PCR as a standard molecular method [76], and colonies infected solely by Nosema ceranae were chosen for the experiment. For the purpose of the experiment, 15 healthy colonies and 15 medium-infected colonies with the infestation level between $140.77 \times 10^{4}( \pm 24.86)$ and $166.4 \times 10^{4}$ $( \pm 23.94)$ Nosema copy number/bee were selected. In each apiary, colonies were divided into 6 groups, i.e., (F1) 5 colonies as control, untreated group with healthy honeybees, (F2) 5 colonies with healthy honeybees fed with E. senticosus extract in the concentration of $0.4 \mathrm{mg} / \mathrm{mL},(\mathrm{F} 3) 5$ colonies with healthy honeybees fed with E. senticosus extract in the concentration of $0.9 \mathrm{mg} / \mathrm{mL}$, (F4) 5 untreated colonies with Nosema-infected honeybees, (F5) 5 colonies with Nosema-infected honeybees fed with E. senticosus extract in the concentration of $0.4 \mathrm{mg} / \mathrm{mL}$ and (F6) 5 colonies with Nosema-infected honeybees fed with E. senticosus extract in the concentration of $0.9 \mathrm{mg} / \mathrm{mL}$. The treated colonies were fed the sucrose solution with extracts four times, twice in spring (1-15 April 2017, 1-15 April 2018), and twice in late summer (1-15 September 2017, 1-15 September 2018). Dead bees from winter debris were collected from each studied colony during February of 2018 and 2019, weighted and the level of Nosema and type of infection were estimated. The level of $N$. ceranae infection in honeybee colonies was measured in September 2017, May 2018 and September 2018. For this purpose, at least 50 foragers at the sealed entrance of the hive were collected from each hive around noon [85]. Furthermore, first honey collected from each studied colony in May/June of 2017 and 2018 was checked for the presence of E. senticosus extract residues using HPLC-DAD.

4.13.2. Impact of the Pre-Treatment of Nosema ceranae Spores with Eleutherococcus Extracts on the Spores' Viability

The spore pre-treatment was performed similarly to previously described methods [58]. The intestines from 30 naturally $N$. ceranae-infected honeybees were isolated to obtain a fresh spore solution. The presence of the N. ceranae DNA in the solution was proven by DNA analysis. After isolation, the intestines were ground in phosphate-buffered saline (PBS), filtered through sterile mesh and washed twice with PBS. Next, spores' suspension in the sucrose:water solution (1:1 w:v) was divided into three parts: (1) left untreated, (2) suspended in E. senticosus extract in the concentration of $0.4 \mathrm{mg} / \mathrm{mL}$ and (3) suspended in E. senticosus extract in the concentration of $0.9 \mathrm{mg} / \mathrm{mL}$. These three spores' suspensions were incubated on a rotary shaker $(160 \mathrm{rpm})$ for $20 \mathrm{~h}$ at $25^{\circ} \mathrm{C}$. After the specified time, the spores were centrifuged for $15 \mathrm{~min}$ at $4000 \mathrm{rpm}$ and washed extensively using sucrose:water solution $(1: 1 \mathrm{w}: \mathrm{v})$. The procedure was repeated at least four times to remove any extract residues. All spore pre-treatments were carried out in parallel with controls, under exactly the same conditions using the fresh spore suspension without any extracts. The obtained spore solutions were divided into three portions. One mixed with sugar syrup was used to infect honeybees, the second was taken for the viability control and the third to the cell wall analysis using Scanning Electron Microscopy (SEM).

\subsubsection{Nosema Spores' Viability Control}

The spores' viability control was performed according to previous studies [58] using SYTO 9 and propidium iodide. Quantifying spore viability was in accordance with Peng et al. [86], the spore samples were observed using the Axiovert 200M fluorescence microscope (Zeiss, Pliening, Germany).

\subsubsection{The Nosema Spore Cell Wall Analysis Under Scanning Electron Microscopy (SEM)}

The SEM analysis (using VEGA LMU, TESCAN, s.r.o., Brno, Czech Republic) was performed similarly to previous studies [14]. A SEM portion of spores was fixed during $24 \mathrm{~h}$ in $5 \%$ gluteraldehyde 
$(v / v)$ in $0.1 \mathrm{M}$ phosphate buffer $\mathrm{pH} 7.3$ for SEM. Then, the sample was washed in phosphate buffer prior to post-fixation in $1 \%$ osmium tetraoxide in $0.1 \mathrm{M}$-phosphate buffer for $24 \mathrm{~h}$ followed by washing in the same buffer. SEM samples were dehydrated by immersion for $15 \mathrm{~min}$, each in fresh solutions of $30 \%, 50 \%, 75 \%, 90 \%$ and $100 \%$ acetone, and critical point-dried. The dried samples were mounted on specimen stubs using a double-sided adhesive tape and coated with gold. Coated samples were viewed under a VEGA LMU scanning microscope at $30 \mathrm{KV}$, measured and photographed.

\subsection{Statistical Analyses}

The analysis of variance (ANOVA) and simple correlations were carried out at the significance level of $\alpha=0.05$ using Statistica software (version 12.0, StatSoft Inc., Tulsa, OK, USA). Four types of tests were analysed: "Screening of commercial plant extracts", "Screening for the best method to obtain the Eleutherococcus extract", "Screening for the best Eleutherococcus dose", and "Additional tests". Tukey tests (one-way ANOVA, Statistica version 12.0, StatSoft Inc., Tulsa, OK, USA) at the significance level of $\alpha=0.05$ for all type of tests were used.

\section{Conclusions and a Future Perspective}

Eleutherococcus senticosus extract decreased the level of honeybee nosemosis, both after the infection as the curing treatment, and when used as prophylaxis. E. senticosus is a recognised plant-based adaptogen, so the mechanism of its effect on honeybees may be supposed to be similar to the one in other animals, including humans. The tested extracts did not affect Nosema spores' viability or ability to infect honeybees. Therefore, there must be other mechanisms that cause administration of E. senticosus extracts to lengthen honeybee lifespan and limit the development of nosemosis. The hemolymph of Nosema-infected honeybees treated with E. senticosus extracts had much higher amounts of PO in comparison to honeybees untreated with E. senticosus extracts. We hypothesised that there is a synergism of all compounds present in the extract; nevertheless, the influence of eleutherosides (eleutheroside B + E) as the main extract ingredients on the honeybee immune system might be the most powerful, especially because adaptogens act in small doses, which was proven in this work as the minimum effective dose contained c.a. $5.76 \mu \mathrm{g}$ of eleutheroside B, $2.56 \mu \mathrm{g}$ of eleutheroside E and $0.07 \mu \mathrm{g}$ of naringenin. The effects of eleutherosides and/or naringenin should be checked in further studies conducted on pure substances. In the future research, the administration of eleutherosides would thus be of interest. However, because of a medium solubility of eleutherosides in the aqueous solutions, the best option seems to be the use of the natural deep eutectic solvents (NADES) as non-toxic solvents. Presently, we know that sugar should be considered as a solvent, i.e., a syrup will extract compounds from plant material other than water. In particular, medium polar compounds like eleutherosides should be quite easily soluble in sugar-derived NADES. All these state-of-the-art research findings, from in vitro to nature, should be taken into account when drafting protocols for prospective honeybee medicament tests.

\section{Highlights}

Eleutherosides benefit honeybees. E. senticosus extracts had similar adaptogenic effects on honeybees as on other animals, including humans.

E. senticosus extract decreased the level of nosemosis, both after the infection-as the curing treatment, and when used as prophylaxis.

The minimum effective dose, i.e., $0.4 \mathrm{mg} / \mathrm{mL}$ of E. senticosus extract, contained $5.76 \mu \mathrm{g} / \mathrm{mL}$ of eleutheroside B, $2.56 \mu \mathrm{g} / \mathrm{mL}$ of eleutheroside $\mathrm{E}$ and $0.07 \mu \mathrm{g} / \mathrm{mL}$ of naringenin and proved to be optimal for honeybee nosemosis treatment and prophylaxis.

Honeybees fed with E. senticosus extracts and infected with Nosema spp. spores had higher PO levels than those in control groups of Nosema-infected insects fed with the pure sucrose solution.

Honeybee colonies which had been administered E. senticosus extract had lower winter debris and had lower nosemosis levels. 
The active compounds' concentration in E. senticosus extract is stable and effective for at least two years.

A combination of results from honeybee survival, disease development and feeding preferences should be considered while drafting prospective honeybee medicament tests.

Supplementary Materials: The following are available online: Table S1. Descriptions of acronyms defined in Section 4.10.1. Cage tests: Screening of commercial plant extracts. Table S2. Descriptions of acronyms defined in Section 4.10.2. Cage tests: Screening for the best method to obtain the Eleutherococcus extract. Table S3. Descriptions of acronyms defined in Section 4.10.3. Cage tests: Screening for the best Eleutherococcus dose. Table S4. Determination of eleutherosides B, E and naringenin in the biologically active extracts, freshly extracted and after 2-year storage (mg/g dry extract). Figure S1. Results of Additional tests. Figure S2. Exemplary images of cages from the cage tests and apiary with the experimental colonies. Figure S3. An exemplary chromatogram of the eleutheroside $\mathrm{B}$ and $\mathrm{E}$ in honey.

Author Contributions: A.A.P. conceived and designed the study, conducted experiments on honeybees, and prepared the manuscript. D.Z. prepared extracts, analysed samples for eleutherosides residue content, and prepared the manuscript. Both authors contributed to the interpretation of results and writing of the original draft and the revised version of manuscript. All authors have read and agreed to the published version of the manuscript.

Funding: This research received no external funding.

Acknowledgments: Publication of the article was financed by the Polish National Agency for Academic Exchange under the Foreign Promotion Programme (NAWA), for A.A.P. (bee-research.umcs.pl; Api Lab UMCS PPI/PZA/2019/1/00039).

Conflicts of Interest: The authors declare no conflict of interest.

\section{References}

1. Aslan, C.E.; Liang, C.T.; Galindo, B.; Kimberly, H.; Topete, W. The role of honey bees as pollinators in natural areas. Nat. Areas J. 2016, 36, 478-488. [CrossRef]

2. Prasad, P.Y.; Mackereth, R.W.; Hanley, R.S.; Qin, W. Honey Bees (Apis mellifera L.) and Pollination Issues: Current status, impacts and potential drivers of decline. J. Agric. Sci. 2015, 7, 93.

3. Zalasiewicz, J.; Waters, C.N.; Summerhayes, C.P.; Wolfe, A.P.; Barnosky, A.D.; Cearreta, A.; Crutzen, P.; Ellis, E.; Fairchild, I.J.; Gałuszka, A.; et al. The Working Group on the Anthropocene: Summary of evidence and interim recommendations. Anthropocene 2017, 19, 55-60. [CrossRef]

4. Crutzen, P.J. Geology of mankind. Nature 2002, 415, 23. [CrossRef]

5. Crutzen, P.J.; Stoermer, E.F. The Anthropocene. Global Change Newsletter. Int. Geosph. Biosph. Programme 2000, 41, 17-18.

6. Ceballos, G.; Ehrlich, P.R. The misunderstood sixth mass extinction. Science 2018, 360, 1080-1081.

7. Pimm, S.L.; Jenkins, C.N.; Abell, R.; Brooks, T.M.; Gittleman, J.L.; Joppa, L.N.; Raven, P.H.; Roberts, C.M.; Sexton, J.O. The biodiversity of species and their rates of extinction, distribution, and protection. Science 2014, 344, 1246752. [CrossRef]

8. Hallmann, C.A.; Sorg, M.; Jongejans, E.; Siepel, H.; Hofland, N.; Schwan, H.; Stenmans, W.; Müller, A.; Sumser, H.; Hörren, T.; et al. More than 75 percent decline over 27 years in total flying insect biomass in protected areas. PLoS ONE 2017, 12, e0185809. [CrossRef]

9. Sánchez-Bayo, F.; Wyckhuys, K.A.G. Worldwide decline of the entomofauna: A review of its drivers. Biol. Conserv. 2019, 232, 8-27. [CrossRef]

10. Higes, M.; Martín, R.; Meana, A. Nosema ceranae, a new microsporidian parasite in honeybees in Europe. J. Invertebr. Pathol. 2006, 92, 93-95. [CrossRef]

11. Fries, I.; Martín, R.; Meana, A.; García-Palencia, P.; Higes, M. Natural infections of Nosema ceranae in European honey bees. J. Apic. Res. 2006, 45, 230-233. [CrossRef]

12. Chemurot, M.; Smet, L.; Brunain, M.; De Rycke, R.; de Graaf, D.C. Nosema neumanni n. sp. (Microsporidia, Nosematidae), a new microsporidian parasite of honeybees, Apis mellifera in Uganda. Eur. J. Protistol. 2017, 61, 13-19. [CrossRef] [PubMed]

13. Panek, J.; Paris, L.; Roriz, D.; Mone, A.; Dubuffet, A.; Delbac, F.; Diogon, M.; El Alaoui, H. Impact of the microsporidian Nosema ceranae on the gut epithelium renewal of the honeybee, Apis Mellifera. J. Invertebr. Pathol. 2018, 159, 121-128. [CrossRef] [PubMed] 
14. Ptaszyńska, A.A.; Borsuk, G.; Mułenko, W.; Demetraki-Paleolog, J. Differentiation of Nosema apis and Nosema ceranae spores under Scanning Electron Microscopy (SEM). J. Apicult. Res. 2014, 53, 537-544. [CrossRef]

15. Ptaszyńska, A.A.; Gancarz, M.; Hurd, P.J.; Borsuk, G.; Wiącek, D.; Nawrocka, A.; Strachecka, A.; Załuski, D.; Paleolog, J. Changes in the bioelement content of summer and winter western honeybees (Apis mellifera) induced by Nosema ceranae infection. PLoS ONE 2018, 13, e0200410. [CrossRef]

16. Huang, Q.; Evans, J.D. Targeting the honey bee gut parasite Nosema ceranae with siRNA positively affects gut bacteria. BMC Microbiol. 2020, 20, 258. [CrossRef]

17. Ptaszyńska, A.A.; Paleolog, J.; Borsuk, G. Nosema ceranae Infection Promotes Proliferation of Yeasts in Honey Bee Intestines. PLoS ONE 2016, 11, e0164477. [CrossRef]

18. Copley, T.R.; Jabaji, S.H. Honeybee glands as possible infection reservoirs of Nosema ceranae and Nosema apis in naturally infected forager bees. J. Appl. Microbiol. 2012, 112, 15-24. [CrossRef]

19. Wang, D.I.; Moeller, F.E. Ultrastructural changes in the hypopharyngeal gland of worker honey bees infected by Nosema apis. J. Invert. Pathol. 1971, 17, 308-320. [CrossRef]

20. Ptaszyńska, A.A.; Borsuk, G.; Anusiewicz, M.; Mułenko, W. Location of Nosema spp. spores within body of honey bee. Med. Weter. 2012, 68, 618-621.

21. Lecocq, A.; Jensen, A.B.; Kryger, P.; Nieh, J.C. Parasite infection accelerates age polyethism in young honey bees. Sci. Rep. 2016, 6, 22042. [CrossRef] [PubMed]

22. Tofilski, A.; Kopel, J. The influence of Nosema apis on maturation and flight activity of honey bee drones. Pszczel. Zesz. Nauk. 1996, 40, 55-60.

23. Peng, Y.; Baer-Imhoof, B.; Millar, A.H.; Baer, B. Consequences of Nosema apis infection for male honeybees and their fertility. Sci. Rep. 2015, 5, 10565. [CrossRef] [PubMed]

24. Adler, L.S. The ecological significance of toxic nectar. Oikos 2001, 91, 409-420. [CrossRef]

25. Burnham, A.J. Scientific Advances in Controlling Nosema ceranae (Microsporidia) Infections in Honey Bees (Apis mellifera). Front. Vet. Sci. 2019, 6, 79. [CrossRef] [PubMed]

26. Chen, X.; Wang, S.; Xu, Y.; Gong, H.; Wu, Y.; Chen, Y.; Zheng, H. Protective potential of Chinese herbal extracts against microsporidian Nosema ceranae, an emergent pathogen of western honeybees, Apis mellifera $\mathrm{L}$. J. Asia Pac. Entomol. 2019. [CrossRef]

27. Kim, J.H.; Park, J.K.; Lee, J.K. Evaluation of antimicrosporidian activity of plant extracts on Nosema ceranae. J. Apic. Sci. 2016, 60, 167-178. [CrossRef]

28. Giacomini, J.J.; Leslie, J.; Tarpy, D.; Palmer-Young, E.; Irwin, R.; Adler, L.S. Medicinal value of sunflower pollen against bee pathogens. Sci. Rep. 2018, 8. [CrossRef]

29. Bravo, J.; Carbonell, V.; Sepúlveda, B.; Delporte, C.; Valdovinos, C.E.; MartínHernández, R.; Higes, M. Antifungal activity of the essential oil obtained from Cryptocarya alba against infection in honey bees by Nosema ceranae. J. Invertebr. Pathol. 2017, 149, 141-147. [CrossRef]

30. Arismendi, N.; Vargas, M.; López, M.D.; Barría, Y.; Zapata, N. Promising antimicrobial activity against the honey bee parasite Nosema ceranae by methanolic extracts from Chilean native plants and propolis. J. Apic. Res. 2018, 57, 522-535. [CrossRef]

31. Ptaszyńska, A.A.; Borsuk, G.; Mułenko, W.; Wilk, J. Impact of vertebrate probiotics on honeybee yeast microbiota and on the course of nosemosis. Med. Weter. 2016. [CrossRef]

32. Dumitru, A.; Chioveanu, G.; Ionita, M.; Dobre, G.; Mitrea, I.L. "In vitro" studies on using natural essential oils in treatment of nosemosis in honeybees: Determination of the therapeutic Dose. Sci. Work. Vet. Medic. Ser. C 2017, 63, 165-170.

33. Mura, A.; Pusceddu, M.; Theodorou, P.; Angioni, A.; Floris, I.; Paxton, R.J.; Satta, A. Propolis Consumption reduces Nosema ceranae infection of European honeybees (Apis mellifera). Insects 2020, 11, 124. [CrossRef]

34. Palmer-Young, E.C.; Tozkar, C.Ö.; Schwarz, R.S.; Chen, Y.; Irwin, R.E.; Adler, L.S.; Evans, J.D. Nectar and Pollen Phytochemicals Stimulate Honey Bee (Hymenoptera: Apidae) Immunity to Viral Infection. J. Econ. Entomol. 2017, 110, 1959-1972. [CrossRef] [PubMed]

35. Bernklau, E.; Bjostad, L.; Hogeboom, A.; Carlisle, A.H.S.A. Dietary Phytochemicals, Honey Bee Longevity and Pathogen Tolerance. Insects 2019, 10, 14. [CrossRef] [PubMed]

36. Porrini, M.P.; Garrido, P.M.; Gende, L.B.; Rossini, C.; Hermida, L.; Marcángeli, J.A.; Eguaras, M.J. Oral administration of essential oils and main components: Study on honeybee survival and Nosema ceranae development. J. Apic. Res. 2017, 56, 616-624. [CrossRef] 
37. Maistrello, L.; Lodesani, M.; Costa, C.; Leonardi, F.; Marani, G.; Caldon, M.; Mutinelli, F.; Granato, A. Screening of natural compounds for the control of nosema disease in honeybees (Apis mellifera). Apidologie 2008, 39, 436-445. [CrossRef]

38. Huang, W.-F.; Solter, L.F.; Yau, P.M.; Imai, B.S. Nosema ceranae Escapes Fumagillin Control in Honey Bees. PLoS Pathog. 2013, 9, e1003185. [CrossRef]

39. Williams, G.R.; Sampson, M.A.; Shutler, D.; Rogers, R.E. Does fumagillin control the recently detected invasive parasite Nosema ceranae in western honey bees (Apis mellifera)? J. Invertebr. Pathol. 2008, 99, 342-344. [CrossRef]

40. van den Heever, J.P.; Thompson, T.S.; Curtis, J.M.; Ibrahim, A.; Pernal, S.F. Fumagillin: An overview of recent scientific advances and their significance for apiculture. J. Agric. Food Chem. 2014, 62, 2728-2737. [CrossRef]

41. Dimpfel, W.; Schombert, L.; Keplinger-Dimpfel, I.K.; Panossian, A. Effects of an adaptogenic extract on electrial activity of the brain in elderly subjects with mild cognitive impairment: A randomized, double-blind, placebo-controlled, two-armed cross-over study. Pharmaceuticals 2020, 13, 45. [CrossRef] [PubMed]

42. Cieśla, Ł.; Waksmundzka-Hajnos, M.; Załuski, D.; Smolarz, H.; Hajnos, M. HPTLC-densitometric method for determination of eleutherosides B, E and E1 in different Eleutherococcus species. J. Chromatogr. Sci. 2011, 49, 182-188. [CrossRef]

43. Nawrot-Hadzik, I.; Choromańska, A.; Abel, R.; Preissner, R.; Saczko, J.; Matkowski, A.; Hadzik, J. Cytotoxic Effect of Vanicosides A and B from Reynoutria sachalinensis against Melanotic and Amelanotic Melanoma Cell Lines and in silico Evaluation for Inhibition of BRAFV600E and MEK1. Int. J. Mol. Sci. 2020, 21, 4611. [CrossRef] [PubMed]

44. Baczek, K. Accumulation of biologically active compounds in Eleuthero (Eleutherococcus senticosus /Rupr. et Maxim./ Maxim.) grown in Poland. Herba Pol. 2009, 55, 7-13.

45. Bączek, K.; Przybył, J.L.; Kosakowska, O.; Węglarz, Z. Accumulation of phenolics in eleuthero (Eleutherococcus senticosus (Rupr. t Maxim.) Maxim.) as affected by plant development. Acta Sci. Pol. Technol. Cultus. 2017, 16, 89-99.

46. Bączek, K. Diversity of Eleutherococcus genus in respect of biologically active compounds accumulation. Herba Pol. 2014, 60, 1-10.

47. Ahn, J.; Um, M.Y.; Lee, H.; Jung, C.H.; Heo, S.H.; Ha, T.Y. Eleutheroside E, an active component of Eleutherococcus senticosus, ameliorates insulin resistance in type 2 diabetic $\mathrm{db} / \mathrm{db}$ mice. Evid. Complement. Altern. Med. 2013, 1-9. [CrossRef]

48. Załuski, D.; Olech, M.; Kuźniewski, R.; Verpoorte, R.; Nowak, R.; Smolarz, H.D. LC-ESI-MS/MS profiling of phenolics from Eleutherococcus spp. inflorescences, structure-activity relationship as antioxidants, inhibitors of hyaluronidase and acetylcholinesterase. Saudi Pharm. J. 2017, 25, 734-743.

49. Venkateswara, R.P.; Kiran, S.D.V.S.; Rohini, P.; Bhagyasree, P. Flavonoid: A review on Naringenin. J. Pharmacog. Phytochemistr. 2017, 6, 2778-2783.

50. Borges, D.; Guzman-Novoa, E. Goodwin PH (2020) Control of the microsporidian parasite Nosema ceranae in honeybees (Apis mellifera) using nutraceutical and immuno-stimulatory compounds. PLoS ONE 2020, 15, e0227484. [CrossRef]

51. Grandjean, P. Paracelsus Revisited: The Dose Concept in a Complex World. Basic. Clin. Pharmacol. Toxicol. 2016, 119, 126-132. [CrossRef] [PubMed]

52. Porrini, M.P.; Fernández, N.J.; Garrido, P.M.; Gende, L.B.; Medici, S.K.; Eguaras, M.J. In vivo evaluation of antiparasitic activity of plant extracts on Nosema ceranae (Microsporidia). Apidologie 2011, 42, 700-707. [CrossRef]

53. Pohorec, K. Laboratory studies on the effect of standardized Artemisia absinthium L. extract on Nosema apis infection in the worker Apis mellifera. J. Apis. Sci. 2004, 48, 131-136.

54. Damiani, N.; Fernández, N.J.; Porrini, M.P.; Gende, L.B.; Álvarez, E.; Buffa, F.; Brasesco, C.; Maggi, M.D.; Marcangeli, J.A.; Eguaras, M.J. Laurel leaf extracts for honeybee pest and disease management: Antimicrobial, microsporicidal, and acaricidal activity. Parasitol. Res. 2014, 113, 701-709. [CrossRef] [PubMed]

55. Załuski, D.; Janeczko, Z. Variation in phytochemicals and bioactivity of the fruits of Eleutherococcus species cultivated in Poland. Nat. Prod. Resear. 2015, 29, 2207-2211. [CrossRef] [PubMed]

56. Botías, C.; Martín-Hernández, R.; Meana, A.; Higes, M. Screening alternative therapies to control Nosemosis type C in honey bee (Apis mellifera iberiensis) colonies. Res. Vet. Sci. 2013, 95, 1041-1045. [CrossRef] 
57. Tauber, J.P.; Collins, W.R.; Schwarz, R.S.; Chen, Y.; Grubbs, K.; Huang, Q.; Lopez, D.; Peterson, R.; Evans, J.D. Natural Product Medicines for Honey Bees: Perspective and Protocols. Insects 2019, 10, 356. [CrossRef]

58. Ptaszyńska, A.A.; Trytek, M.; Borsuk, G.; Buczek, K.; Rybicka-Jasińska, K.; Gryko, D. Porphyrins inactivate Nosema spp. microsporidia. Sci. Rep. 2018, 8, 5523. [CrossRef]

59. Eleftherianos, I.; Revenis, C. Role and Importance of Phenoloxidase in Insect Hemostasis. J. Innate Immun. 2011, 3, 28-33. [CrossRef]

60. Ferrandon, D.; Imler, J.L.; Hetru, C.; Hoffmann, J.A. The Drosophila systemic immune response: Sensing and signalling during bacterial and fungal infections. Nat. Rev. Immunol. 2007, 7, 862-874. [CrossRef]

61. Ptaszyńska, A.A.; Cytryńska, M.; Mułenko, W.; Zdybicka-Barabas, A.; Borsuk, G.; Załuski, D. Plant extracts for use in the treatment of honey bees nosemosis and to enhance bee resistance. PL. 232685, 19 July 2019.

62. Ptaszyńska, A.A.; Borsuk, G.; Zdybicka-Barabas, A.; Cytryńska, M.; Małek, W. Are commercial probiotics and prebiotics effective in the treatment and prevention of honeybee nosemosis C? Parasit. Res. 2016, 115, 397-406. [CrossRef] [PubMed]

63. Andrejko, M.; Zdybicka-Barabas, A.; Cytryńska, M. Diverse effects of Galleria mellonella infection with entomopathogenic and clinical strains of Pseudomonas aeruginosa. J. Invertebr. Pathol. 2014, 115, 14-25. [CrossRef] [PubMed]

64. Zdybicka-Barabas, A.; Mak, P.; Jakubowicz, T.; Cytryńska, M. Lysozyme and defense peptides as suppressors of phenoloxidase activity in Galleria mellonella. Arch. Insect Biochem. Physiol. 2014, 87, 1-12. [CrossRef] [PubMed]

65. Stączek, S.; Zdybicka-Barabas, A.; Pleszczyńska, M.; Wiater, A.; Cytryńska, M. Aspergillus niger $\alpha-1,3-$ glucan acts as a virulence factor by inhibiting the insect phenoloxidase system. J. Invertebr. Pathol. 2020, 171, 107341. [CrossRef] [PubMed]

66. Wojda, I.; Cytryńska, M.; Zdybicka-Barabas, A.; Kordaczuk, J. Insect Defense Proteins and Peptides. In Vertebrate and Invertebrate Respiratory Proteins, Lipoproteins and Other Body Fluid Proteins; Hoeger, U., Harris, J., Eds.; Subcellular Biochemistry: Cham, Switzerland, 2020; Volume 94. [CrossRef]

67. Davydov, M.; Krikorian, A.D. Eleutherococcus senticosus (Rupr. et Maxim.) Maxim. (Araliaceae) as an adaptogen: A closer look. J. Ethnopharmac. 2000, 72, 345-393. [CrossRef]

68. Asea, A.; Kaur, P.; Panossian, A.; Wikman, K.G. Evaluation of molecular chaperons Hsp72 and neuropeptide $\mathrm{Y}$ as characteristic markers of adaptogenic activity of plant extracts. Phytomedicine 2013, 20, 1323-1329. [CrossRef]

69. Traver, B.E.; Williams, M.R.; Fell, R.D. Comparison of within hive sampling and seasonal activity of Nosema ceranae in honey bee colonies. J. Invertebr. Pathol. 2012, 109, 187-193. [CrossRef]

70. Mulholland, G.E.; Traver, B.E.; Johnson, N.G.; Fell, R.D. Individual variability of Nosema ceranae infections in Apis mellifera colonies. Insects 2012, 3, 1143-1155. [CrossRef]

71. Gisder, S.; Hedtke, K.; Möckel, N.; Frielitz, M.-C.; Linde, A.; Genersch, E. Five-year cohort study of Nosema spp. in Germany: Does climate shape virulence and assertiveness of Nosema ceranae? Appl. Environ. Microbiol. 2010, 76, 3032-3038. [CrossRef]

72. Adamczyk, K.; Olech, M.; Abramek, J.; Pietrzak, W.; Kuźniewski, R.; Bogucka-Kocka, A.; Nowak, R.; Ptaszyńska, A.A.; Rapacka-Gackowska, A.; Skalski, T.; et al. Eleutherococcus Species Cultivated in Europe: A New Source of Compounds with Antiacetylcholinesterase, Antihyaluronidase, Anti-DPPH, and Cytotoxic Activities. Oxidative Med. Cell. Longev. 2019. [CrossRef]

73. Baker, H.G.; Baker, I. Studies of nectar-constitution and pollinator-plant coevolution. In Coevolution of plants and animals; Gilbert, L.E., Raven, P.H., Eds.; The University of Texas Press: Austin, TX, USA; Springer: Boston, MA, USA, 1975; pp. 100-140.

74. Rhoades, D.F.; Bergdahl, J.C. Adaptive significance of toxic nectar. Am. Nat. 1981, 117, 798-803. [CrossRef]

75. Tumiłowicz, J.; Banaszczak, P. Trees and shrubs of Aquifoliaceae family in Rogów and Glinna arboreta. Rocz. Dendrol. 2007, 55, 41-56.

76. eFloras. Missouri Botanical Garden, St. Louis, MO \& Harvard University Herbaria, Cambridge, MA. Available online: http://www.efloras.org (accessed on 1 October 2015).

77. Fries, I.; Chauzat, M.-P.; Chen, Y.-P.; Doublet, V.; Genersch, E.; Gisder, S.; Higes, M.; Mcmahon, D.P.; Martínhernández, R.; Natsopoulou, M.; et al. Standard methods for nosema research. In The COLOSS BEEBOOK: Volume II: Standard Methods for Apis Mellifera Pest and Pathogen Research; Dietemann, V., Ellis, J.D., Neumann, P., Eds.; Taylor and Francis Ltd.: Milton Park, UK, 2013; Volume 51. [CrossRef] 
78. Martín-Hernández, R.; Meana, A.; Prieto, L.; Salvador, A.M.; Garrido-Bailón, E.; Higes, M. Outcome of colonization of Apis mellifera by Nosema ceranae. Appl. Environ. Microbiol. 2007, 73, 6331-6338. [CrossRef] [PubMed]

79. Cantwell, G.E. Standard methods for counting Nosema spores. Am. Bee J. 1970, 110, 222-223.

80. Hornitzky, M. Nosema Disease-Literature review and three surveys of beekeepers-Part 2; Rural Industries Research and Development Corporation: New South Wales, Australia, 2008.

81. Bourgeois, A.L.; Rinderer, T.E.; Beaman, L.D.; Danka, R.G. Genetic detection and quantification of Nosema apis and N. ceranae in the honey bee. J. Invertebr. Pathol. 2010, 103, 53-58. [CrossRef]

82. Evans, J.D.; Schwarz, R.; Chen, Y.; Budge, G.; Cornman, R.; Rúa, P.D.; Miranda, J.D.; Forêt, S.; Foster, L.; Gauthier, L.; et al. Standard methodologies for molecular research in Apis mellifera. In The COLOSS BEEBOOK, Volume I: Standard Methods for Apis Mellifera Research V; Dietemann, J.D., Ellis, P.N., Eds.; Taylor and Francis Ltd.: Milton Park, UK, 2013; Volume 52. [CrossRef]

83. Chen, Y.; Evans, J.; Zhou, L.; Boncristiani, H.; Kimura, K.; Xiao, T.; Litkowski, A.M.; Pettis, J. Asymmetrical coexistence of Nosema ceranae and Nosema apis in honey bees. J. Invertebr. Pathol. 2009, 101, 204-209. [CrossRef]

84. Chen, Y.P.; Higgins, J.A.; Feldlaufer, M.F. Quantitative real-time reverse transcription PCR analysis of deformed Wing virus infection in the honeybee (Apis mellifera L.). Appl. Environ. Microbiol. 2005, 71, 436-441. [CrossRef]

85. Meana, A.; Martín-Hernández, R.; Higes, M. The reliability of spore counts to diagnose Nosema ceranae infections in honey bees. J. Apic. Res. Bee World 2010, 49, 212-214. [CrossRef]

86. Peng, Y.; Lee-Pullen, T.F.; Heel, K.; Millar, A.H.; Baer, B. Quantifying spore viability of the honey bee pathogen Nosema apis using flow cytometry. Cytom. Part A 2014, 85, 454-462. [CrossRef]

Sample Availability: Samples of honeybees and extracts are available from the authors.

(C) 2020 by the authors. Licensee MDPI, Basel, Switzerland. This article is an open access article distributed under the terms and conditions of the Creative Commons Attribution (CC BY) license (http://creativecommons.org/licenses/by/4.0/). 